\title{
Accuracy and reliability: a computational tool to minimise steel mass and carbon emissions at early-stage structural design
}

\author{
Bernardino D'Amico ${ }^{\mathrm{a}, \mathrm{b}, *}$, Francesco Pomponi ${ }^{\mathrm{a}, \mathrm{b}}$ \\ ${ }^{a}$ REBEL (Resource Efficient Built Environment Lab) \\ ${ }^{b}$ School of Engineering and the Built Environment, Edinburgh Napier University, UK
}

\begin{abstract}
Building structures often represent the element with the largest mass in a building project, with significant effects on the buildings life cycle environmental impacts. Amongst structural materials, steel is characterised by its suitability to a large number of structures as well as a highly pollutant supply chain. Therefore, even a small reduction of the amount of steel currently used in building structures, would undoubtedly be beneficial towards the mitigation of environmental impacts. This paper presents a computational tool that aims to help practitioners to design material-efficient structures for multi-storey buildings frames. The tool is based on an optimisation framework, which -given a small set of input parameters defining the overall frame geometry and the system of loadings- seeks for optimised cross-sections for each structural member, based on a finite set of commercially available section profiles. Results are fully compliant with British and European standards for structural design. The user can therefore quickly and reliably assess a wide range of alternative frame layouts in a nearly real-time frame. To avoid misleading the decision-maker with very definite numbers, both structural mass and embodied carbon coefficients are considered along with their uncertainty through Montecarlo simulation. The final output consists of a probability density function of the embodied carbon for the specific structural design under consideration. The mathematical model which underpins the tool has been extensively validated. Results of an application to a practical example show a carbon emissions reduction potential of $23 \%$. To maximise the impact of the research findings, the described work has been implemented into a plug-in tool for a widely used CAD software. This will help practitioners to take into account embodied carbon consideration early on in the design process when the room for improvement is greatest and the economic repercussions of design changes are low. This tool represents a fundamental first step to translate research on embodied carbon reduction into a means that is useful to, and usable by, industry professionals to mitigate building-related carbon emissions and progress towards national and international carbon targets.
\end{abstract}

Keywords: Embodied Carbon, GHG emissions, Parametric, Early stage, Design, Optimisation, Steel, Buildings, Frame.

\footnotetext{
${ }^{*}$ Corresponding author

Email addresses: b.damico@napier.ac.uk (Bernardino D'Amico), f.pomponi@napier.ac.uk (Francesco Pomponi)
} 


\section{Introduction}

The impacts buildings have on energy, carbon emissions, and resource use worldwide are vast. In Europe, they are responsible for $42 \%$ of the energy demand, $50 \%$ of extracted materials, $35 \%$ of greenhouse gases (GHGs) emissions [1], and $32 \%$ of the waste flows [2]. Global figures are also in line with these [3]. Over the past decades, a concentrated effort targeted the reduction of the operational impacts of buildings, primarily in terms of energy demand reduction. This has left out the embodied carbon impacts, ${ }^{1}$ which now account for an ever greater share of the whole-life impacts caused by buildings [4]. While negative embodied externalities affect a number of environmental impact categories, it is most common in practice to narrow these down to a single unit of assessment [5], that is, carbon dioxide equivalent emissions [6]. This also resonates with the international debate over climate change and global warming, which are unequivocally driven by anthropogenic carbon emissions [7].

Within the embodied carbon (EC) impacts of buildings, the greatest share is attributed to the building structure [8]. In particular, the most carbon intensive activities are those related to resource extraction and transportation, as well as processing and manufacturing [4]. Within the strategies to mitigate embodied carbon in buildings, improvements in design are amongst the most promising [4]. These generally materialise in increased efficiency and a more effective use of the resources utilised.

\subsection{The potential of structural design optimisation}

In this context, one of the most promising steps to mitigate the embodied carbon of a building is arguably the reduction of the total mass of the structural material being used [9], because materials can account for up to 80-90\% of the total building embodied GHG emissions [10]. Although other approaches exist such as, for instance, an ontology-based approach for low-carbon structural design [11], this task falls into the domain of structural optimisation [12], whose main concern is to develop procedures and methods (preferably in an automated fashion) aimed at finding those design solutions for which the smallest amount of material is used, and at the same time, all the constrains and limitations imposed by design requirements are fulfilled.

Reinforced concrete, steel and timber are the three materials mostly used for building structures. The steel industry accounts for roughly $2.5 \mathrm{Gt}$ of carbon dioxide $\left(\mathrm{CO}_{2}\right)$ emission [13] which represent $25 \%$ of the total global $\mathrm{CO}_{2}$ emissions. Nearly half of that steel is used in building structures [13]. Consequentially, a joint analysis of structural mass and carbon emissions could have significant benefits in terms of environmental impact reduction [14, 15]. Additionally, it has been shown that,

\footnotetext{
${ }^{1}$ Embodied carbon is here defined as the sum of $\mathrm{CO}_{2 \mathrm{e}}$ emissions related to all processes and activities that occur throughout a building's life, from resource extraction and product manufacturing, transportation, construction and installation, through to maintenance and end of life activities.
} 
when compared with other structural materials, steel buildings might have the lowest total weight but have the highest embodied carbon [16], and in general structural steel is a major contributor to embodied carbon in buildings [17].

The focus of this paper is therefore on steel structures, and it aims to translate academic research on structural optimisation and embodied carbon assessment into a user-friendly tool which can be used by professionals in the construction industry at early design stage, when the potential for structural mass and environmental impact reduction is greatest [18]. Given the great uncertainty that surrounds life cycle assessment (LCA) of buildings [19], we adopted a probabilistic approach to estimating the embodied carbon of a steel structure in line with previous research in the field $[20]$.

Academic research has shown the great influence that information visualisation has in driving design practitioners towards sustainability-oriented solutions [21]. However, a limitation identified in existing approaches is the lack of integration into software tools available in the industry today [21]. For these reasons, the tool developed in this research has been driven by both a highly visual component as well as the integration in one of the most widely used tools in the construction industry.

The next section reviews existing approaches and their shortcomings, and introduces the research design, section 3 provides the theoretical underpinnings that have guided the tool development and implementation, and also describes the limitations of the approach developed. Section 4 shows the tool's potential through practical applications and reports on its validation. Section 5 concludes the article by discussing the implications of this research and highlights future research efforts.

\section{Research design}

The application of mathematical optimisation techniques to structural design has found, historically, an extremely fertile ground in academic-led research. Yet, unlike for other industry sectors (such as automotive and aerospace) where even small reductions of weight are positively recognised thanks to the economies of scale of producing vast numbers of identical parts, the building construction industry seems to have not been particularly 'touched' by the subject.

One may argue that because buildings are, in general, the result of a single one-off project, allocating more resources on design improvements would not lead to higher investment returns, despite gains in reduced amount of material. While for highly complex civil engineering structures (such as skyscrapers [22], long span bridges [23] and roofs [24]) an additional (optimisation-related) design cost is overrun by the overall savings in terms of material reduction, for common size building projects it remains preferable to accept a non-optimised design (i.e. using more material than actually needed) as this consents to limit the design effort, and associated labour costs [25]. Nonetheless, 'common' buildings, such as multi-storey steel frames, represent a much bigger share of the built environment compared to complex civil engineering infrastructures, therefore focus must be prioritised on this building typology if a more significant impact on the mitigation of carbon emissions 
in the building sector is to be achieved.

\subsection{Minimum material versus minimum cost}

According to Gibbons [26]: "The labour-related items (e.g. drawing, fabrication, erection), constitute approximately $50 \%$ of the cost of even the simplest steel framed structure [...] least weight structural solutions, very rarely produce the most cost-effective designs." As a result, when designing a steel frame, structural engineers tend to minimise the overall number of different member sizes and sections, usually arranging the columns layout on a regular orthogonal grid pattern to achieve maximum component repetition. This practice is termed as 'rationalisation' [26]. A practical consequence of this is indeed a reduced amount of labour and procurement costs, however construction costs are context dependent and such general rules of thumb might not always represent the best option [27].

Mapping existing trade-offs between two or more conflicting objectives (i.e. material and costs minimisation in this case) can be efficiently handled via multi-objective optimisation, for instance by using heuristic techniques $[28,29,30,31]$. The computational power needed to achieve realtime user-machine interaction, and the level of expert knowledge required for implementation, are perhaps the main reasons why such techniques have not found yet widespread adoption in building structures design.

\subsection{Limiting the design space}

As Baldock points out [32], three main optimisation tasks can be associated with the design of building structures, namely: cross-section optimisation of individual members [33, 34, 35]; geometry optimisation [36, 37, 38], that is for a frame structure, to find the optimal length of its beams and columns; and topology optimisation [39, 40,41,42], i.e. to find the optimal number of structural members and the way in which they connect to each other. In the generalised case, including all three of the above-mentioned design features would be required in order to find a 'truly' global minimum for the structural mass. Nonetheless, the need for 'rationalisation' discussed in section 2.1, as well as additional requirements, coming for instance from the client or architect (i.e. with regard to the plan layout arrangement) can greatly restrict the range of adopted solutions in practice, to a well-established set of frame geometries. For this reason, it was decided in here to focus the optimisation problem of mass minimisation to the cross-sectional design space, hence assuming the frame geometry/topology as input parameters of the problem. Worth nothing that, as empirically demonstrated by Moynihan and Allwood [25], a mass reduction of up to 36\% can be achieved by cross-section optimisation for multi-storey steel frames.

\subsection{A practice-oriented optimisation tool}

Despite the continuously growing academic body of work on novel optimisation methods and their application to most disparate problems of structural engineering (see Ref. [43] for a review of traditional and modern techniques) expert knowledge is indeed required to successfully translate 
these methods into a practical tool usable by the busy engineers. Moreover, it has been shown within the field of environmental impacts of buildings - that academics disseminate their findings through routes that are rarely accessed by practitioners [44]. Therefore, a need exists for a solution addressing the point from a practice-oriented perspective while being grounded in academic rigour. A practitioner who needs to optimise a building structure whilst minimising its embodied carbon emissions is likely to operate within one or more of following constraints:

- Time: which does not allow extensive searches of academic works and successive study of the theory behind.

- Cost: which does not allow to benefit from expert knowledge through, for instance, third-party consultancy.

- Perfectness of information: which does not allow to use existing tools and techniques requiring high specificity/detail in order to perform calculation and optimisation.

For these reasons, the tool described in here has been built by combining programming and optimisation techniques in a novel framework, which enables to overcome all the above restrictions and yet deliver an optimised solution that can be realistically implemented in practice. The tool is limited to designs of steel frames having a rectangular layout plan, with constant span lengths. The tool's theoretical framework and functioning are explained in detail in the next section.

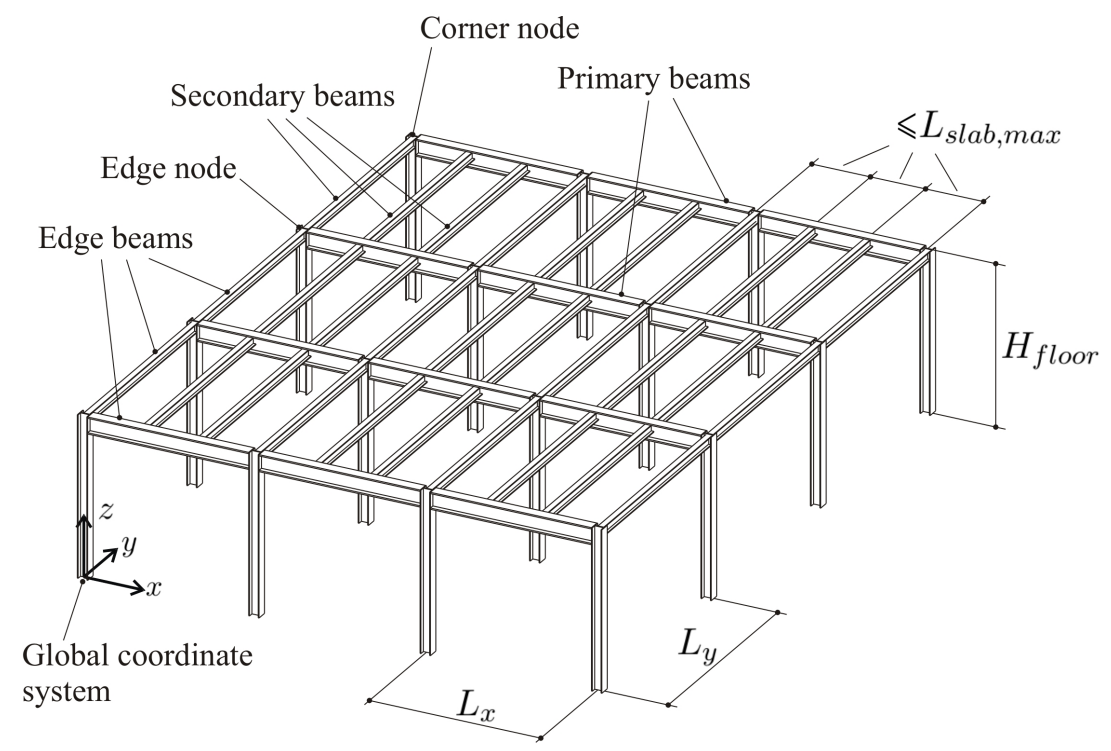

Figure 1: Terms and symbols used in the paper to indicate the various frame components and geometric parameters.

\section{Methodology}

\subsection{Input parameters}

In order to run the tool, a series of input parameters are required. Those inputs allow to define the steel frame geometry and topology, and they provide information on the loading system 
the structure is required to withstand. Two further parameters, related to the Embodied Carbon Coefficient (ECC) of steel, need to be specified as well. The complete list of required inputs is given as follows:

- Geometric parameters: $L_{x}$ and $L_{y}$ indicate respectively the primary and secondary spans of the structural grid, while $L_{\text {slab,max }}$ is the maximum (allowable) span of the floor slabs and $H_{\text {floor }}$ is the inter-storey height (see Figure 1). All expressed in [mm].

- Topological parameters: $n_{x}$ and $n_{y}$ are integers representing the number of bays along the primary and secondary structural grid direction, respectively, whereas $n_{\text {floor }}$ is the number of storeys and $\mathbf{b}$ is a list containing information on the layout of the bracing system.

- Loading parameters (characteristic values):

- Variable loads: $q_{\text {wind }}$ is the wind pressure load, whereas $q_{f l o o r}$ is the imposed floor load, both in $\left[\mathrm{kN} / \mathrm{m}^{2}\right]$.

- Permanent loads: $g_{e n v}$ is the load $[\mathrm{kN} / \mathrm{m}]$ due to the building's envelope walls; $g_{s l a b}$ is the floor slabs' self-weight and $g_{f i n}$ is the floor load due to floor finishes, ceiling, services and partitions, both in $\left[\mathrm{kN} / \mathrm{m}^{2}\right]$.

- ECC parameters: $\mu_{E C}$ and $\sigma_{E C}$ are, respectively, the mean value and standard deviation of the embodied carbon coefficient $\left[\mathrm{kgCO}_{2 \mathrm{e}} / \mathrm{kg}\right]$.

\section{2. 'Simple' frame construction}

Before going on illustrating the theoretical framework, it is useful to clarify an important difference between the two main construction methods structural engineers are faced to choose from, when designing a multi-storey steel frame. Namely: 'simple' frame construction, also referred to as 'braced' or 'pin-jointed' frame, and 'continuous' frame construction, also termed 'rigid' or 'momentresisting' frame. From a structural point of view, one substantial difference between these two methods of construction resides in the way internal bending moments distribute within the system: in continuous frames the beam-to-columns connections are (nominally) fully-clamped, therefore bending moment arising at a given beam's location (i.e. due to the presence of an external load) is redistributed to the surrounding beams and columns. Contrarily, nominally pinned connections

(a)

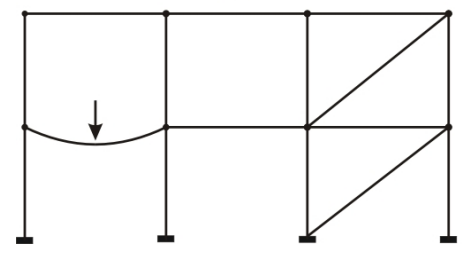

(b)

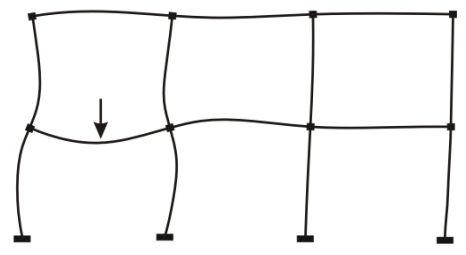

Figure 2: Structural frames schematics: (a) 'simple' frame construction; (b) 'continuous' frame construction. 
are assumed in simple frame construction, therefore only axial forces are transferred to the supporting columns and no bending moment is carried on to the surrounding beams. A schematic representation of such structurally different behaviours is shown in Figure 2.

\subsection{A sequential approach}

A practical implication of dealing with 'simple' frame construction is therefore the absence of bending moment interaction between beams and columns. This enables to design (hence optimise) primary and secondary beams independently from the bearing system of columns and bracing. ${ }^{2}$ Therefore, the optimisation problem of cross-section minimisation for the entire set of structural steel members can be tackled by decomposing it into two separate sub-problems, to be solved in a sequential manner. In a first computing step, the floor system design of least mass (thus weight) is searched for, and once it is found, a second computing step is launched to search for the optimal design of the bearing and lateral stability systems (i.e. columns and bracing) by assuming the (previously found) optimal floor design as a prescribed input data.

\subsection{Floor system optimisation}

The first computing step, i.e. optimisation of the floor system, can be solved in two consecutive tasks: the first concerning to the cross-section minimisation of secondary beams, while the second task focuses on minimising the primary beams' cross-section. A further design simplification comes from the fact that bending moment discontinuity between adjacent beams in a simply supported floor system (as shown in Figure 2) allows to design each beam by only considering the set of loading directly applied onto the beam itself, hence without need to consider for several floor loading patterns, as for continuous beam design [45]. If we also take into account that a constant length $\left(L_{x}\right)$ for all primary beams, and a constant length $\left(L_{y}\right)$ for al secondary beams are provided, then the overall number of different cross-sectional specifications reduces to only four: according to whether we are dealing with a primary or a secondary beam, and to whether it is an edge-beam or an internal beam (see Figure 1).

\subsubsection{Secondary beams}

The uniformly distributed load, $U_{d}$, acting on internal, secondary beams, is derived from the (user-provided) geometrical and loading input values by considering a portion of floor area equal to $\left(L_{x} L_{y}\right) /\left(n_{s, b}+1\right)$ as shown in Figure 3, therefore:

$$
U_{d}=1.35\left[\frac{L_{x}}{\left(n_{s, b}+1\right)}\left(g_{\text {slab }}+g_{\text {fin }}\right)+A_{s, b} \rho \ddot{x}\right]+1.5 \frac{L_{x}}{\left(n_{s, b}+1\right)} q_{\text {floor }}
$$

in which: $\rho=$ density of structural steel (taken as $7850\left[\mathrm{~kg} / \mathrm{m}^{3}\right]$ ); $A_{s, b}=$ secondary beam's crosssectional area; $\ddot{x}=$ gravitational acceleration constant, and $n_{s, b}$ is the number of secondary beams

\footnotetext{
${ }^{2}$ In reality, a very small bending moment arises in (simple frame's) columns as well. This is due to eccentricities between the columns' centroid axis and the connections supporting each beam at its ends.
} 


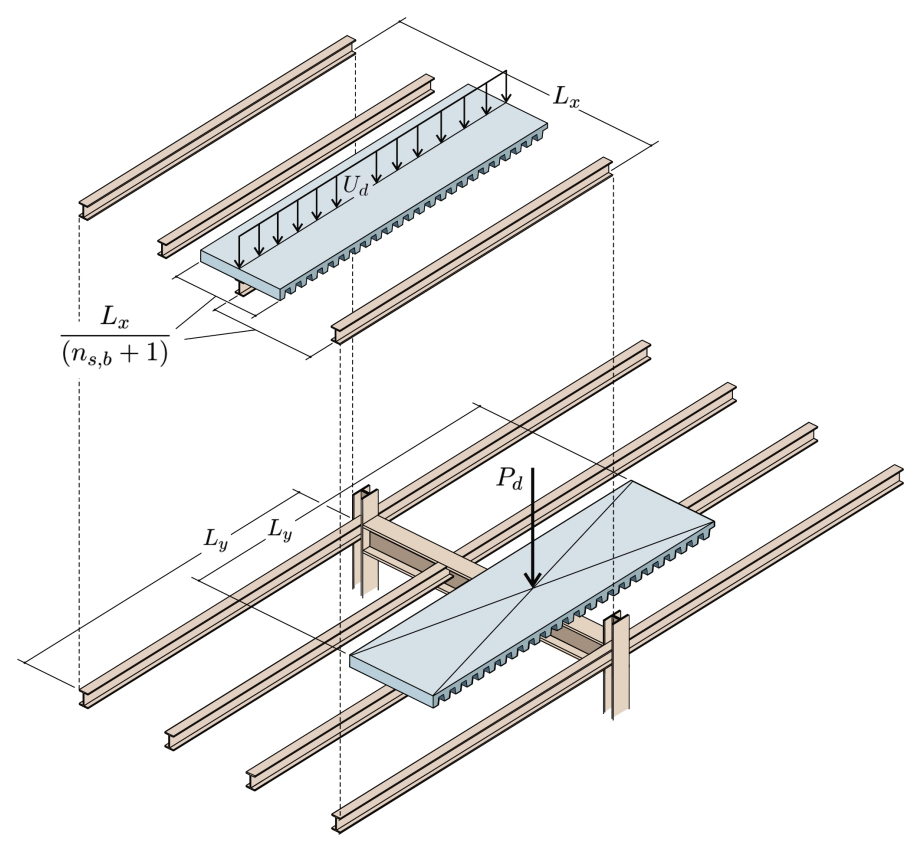

Figure 3: portion of floor area considered in Eq. (1) and Eq. (8) to compute the equivalent uniformly distributed load $U_{d}$ and point-load $P_{d}$ acting, respectively, on each secondary beam and primary beam (except those at the edge).

between each primary bay (i.e. $n_{s, b}=2$ for the frame shown in Figure 1). The value of $n_{s, b}$ is automatically computed as the smallest integer for which, given a certain length of primary span $L_{x}$, the resulting span for the floor slabs will not exceed the allowable $L_{\text {slab,max }}$ value:

$$
n_{s, b}=\max \left\{\begin{array}{l}
0 \\
\text { ceiling }\left(\frac{L_{x}-L_{\text {slab }, \max }}{L_{\text {slab }, \max }}\right)
\end{array}\right.
$$

For a given argument $x$, the function ceiling () in Eq. (2) returns the smallest integer $\geq x$. The numerical values 1.35 and 1.5 in Eq. (1) are partial safety factors for Ultimate Limit State (ULS) design calculations [46], and will appear in the same numerical format in few more equations to follow. They are required to (respectively) convert permanent and variable loads, into corresponding design values.

In order to minimise the cross-sectional area, the beam's resistance against bending $\left(M_{c, R d}\right)$, lateral torsional buckling resistance $\left(M_{b, R d}\right)$ and shear resistance $\left(V_{c, R d}\right)$, as well as the beam deflection against the allowable limit $\left(=L_{y} / 360\right)$ must be all checked [47]. Let express in here the ratio between the design effect (indicated with the subscript $E d$ ) and the design resistance (indicated with the subscript $R d$ ):

$$
\frac{M_{E d}}{M_{c, R d}}-1 \leq 0 \quad ; \quad \frac{M_{E d}}{M_{b, R d}}-1 \leq 0 \quad ; \quad \frac{V_{E d}}{V_{c, R d}}-1 \leq 0 \quad ; \quad \frac{\delta_{E d}}{L_{y} / 360}-1 \leq 0
$$

in which:

$$
M_{E d}=\frac{U_{d} L_{y}^{2}}{8} \quad ; \quad V_{E d}=\frac{U_{d} L_{y}}{2} \quad ; \quad \delta_{E d}=\frac{5 U_{d} L_{y}^{4}}{384 E I}
$$


with $U_{d}$ as from Eq. $(1)^{3}, E=$ steel elastic modulus i.e. $210000\left[\mathrm{~N} / \mathrm{mm}^{2}\right]$, and $I=$ second moment of area of the beam's cross-section. The design check will then consists to make sure that, for a given section profile, all of the inequalities stated in Eqs.(3) are fulfilled.

\subsubsection{Sequential Search algorithm}

In structural design practice of steel frames, engineers mostly rely on catalogues of cross-section profiles to choose from, therefore their choice is based on a finite set of alternatives, represented in here as a list $\mathbf{t}$, with $t$ being the index of the generic item in $\mathbf{t}$. Each item is itself a list containing geometric information (such as area $A$, second moment of area $I$, section modulus etc.) from which the design resistances (and self-weight per unit length) of the corresponding section profile can be derived according to Eurocode procedures [47]. Expressing each left-side term in Eqs. (3), and cross-sectional area $A$, as functions of the section profile index $t$ :

$f_{1}(t)=\frac{M_{E d}}{M_{c, R d}}-1 \quad ; \quad f_{2}(t)=\frac{M_{E d}}{M_{b, R d}}-1 \quad ; \quad f_{3}(t)=\frac{V_{E d}}{V_{c, R d}}-1 \quad ; \quad f_{4}(t)=\frac{\delta_{E d}}{L_{y} / 360}-1$

the optimisation problem of cross-sectional area minimisation can be stated as follows:

$$
\begin{array}{ll}
\text { minimize: } & A(t) \\
\text { subject to : } & \max \left\{f_{1}(t), f_{2}(t), f_{3}(t), f_{4}(t)\right\} \leq 0
\end{array}
$$

If all of the available section profiles within $\mathbf{t}$ are ordered in ascending order according to $A$, e.g. $A(t-1)<A(t)<A(t+1)$, then a Sequential Search algorithm [48] can be employed to find the optimal profile. With the help of Figure 4: starting from the first item $(t=0)$ the algorithm checks whether Eqs. (3) are all fulfilled: if not (the section is too weak or too flexible), then it passes on to check the next item and so on until it finds the section index $t$ for which all four of the above mentioned strength and stiffness criteria are met. The item so found corresponds to the optimal cross-section, since, all of the remaining (unchecked) items will all have greater sectional area ${ }^{4}$ and therefore a greater mass per unit length.

The described procedure equally applies to find the optimal cross-section of secondary beams at the edges, except for the value of $U_{d}$, which must be computed by taking into consideration a reduced floor area, as well as the additional load due to the building's envelope walls:

$$
U_{d, e n v}=1.35\left[\frac{L_{x}}{2\left(n_{s, b}+1\right)}\left(g_{s l a b}+g_{f i n}\right)+A_{s, b} \rho \ddot{x}+g_{\text {env }}\right]+1.5 \frac{L_{x}}{2\left(n_{s, b}+1\right)} q_{f l o o r}
$$

It is also worth to note that the section of minimum area so found may not necessarily correspond to the section for which the demand/capacity ratios in Eqs. (3) are minimised. This is because the

\footnotetext{
${ }^{3}$ The fourth inequality in Eqs. (3) is checked for Serviceability Limit States (SLS) [46]. Therefore, $\delta_{E d}$ is computed by setting both partial safety factors equal to unity.

${ }^{4}$ This explains the need to have all the items in $\mathbf{t}$ ordered according to their area section in ascending order.
} 


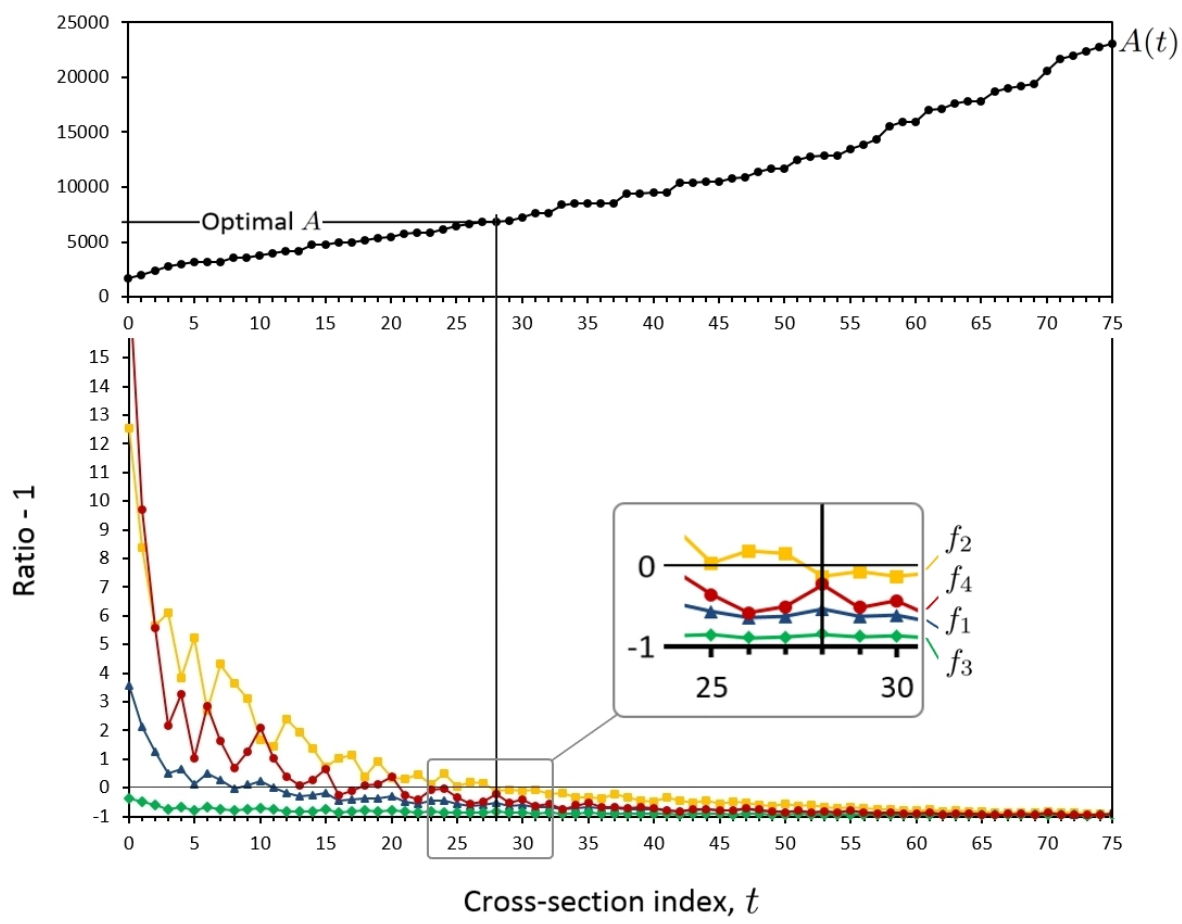

Figure 4: Graphical representation of the optimisation algorithm. The function $A(t)$ shown in Figure is based on the Universal Beam section catalogue [49], whereas the ratios $f_{1}(t)$ to $f_{4}(t)$ are obtained setting the beam's length to $6.5 \mathrm{~m}$ and assuming a uniformly distributed design load of $20 \mathrm{kN} / \mathrm{m}$ for ULS, and $14 \mathrm{kN} / \mathrm{m}$ for SLS respectively.

governing geometric parameter for bending members is the second moment of area section rather than the sectional area.

\subsubsection{Primary beams}

The same Sequential Search procedure described for secondary beams equally applies to find the optimal primary beams' section. Each primary beam will have to withstand a series of $n_{s, b}$ evenly distributed point-loads $P_{d}$, coming from secondary beams surrounding each (internal) primary beam on both sides (see Figure 3):

$$
P_{d}=1.35\left[\frac{L_{x} L_{y}}{\left(n_{s, b}+1\right)}\left(g_{s l a b}+g_{f i n}\right)+A_{s, b} \rho \ddot{x} L_{y}\right]+1.5 \frac{L_{x} L_{y}}{\left(n_{s, b}+1\right)} q_{\text {floor }}
$$

Plus, the primary beam's own self-weight $U_{d^{*}}$ must be considered as well, which is conveniently expressed in here as a load per unit length:

$$
U_{d^{*}}=1.35 A_{p, b} \rho \ddot{x}
$$

with $A_{p, b}$ being the primary beam's cross-sectional area.

Accordingly, the maximum (i.e. mid-span) value of design bending moment, $M_{E d}$, to insert in 
the first two Eqs. (3) is obtained as follows:

$$
M_{E d}= \begin{cases}P_{d} L_{x}\left[\frac{n_{s, b}}{4 n_{s, b}+4}\left(\frac{n_{s, b}}{2}+1\right)\right]+\frac{L_{x}^{2} U_{d^{*}}}{8} & \text { for } n_{s, b}=\text { even } \\ \frac{P_{d} L_{x}}{4}\left(\frac{n_{s, b}+1}{2}\right)+\frac{L_{x}^{2} U_{d^{*}}}{8} & \text { for } n_{s, b}=\text { odd }\end{cases}
$$

while the applied design shear load and mid-span deflection, to insert in the second two Eqs. (3), are taken as:

$$
V_{E d}=\frac{P_{d} n_{s, b}+L_{x} U_{d^{*}}}{2} \quad ; \quad \delta_{E d} \approx \frac{5 L_{x}^{4}}{384 E I}\left(\frac{P_{d} n_{s, b}}{L_{x}}+U_{d^{*}}\right)
$$

Lastly, the same procedure is repeated for primary beams at the edges, except for the value of $P_{d}$, for which a reduced floor area must be considered, and an additional load, due to the building's envelope walls, must be also included. Therefore, for primary edge beams, Eqs. (8) and (9) are replaced respectively by:

$$
P_{d, e n v}=\frac{P_{d}}{2}
$$

and:

$$
U_{d^{*}, \text { env }}=1.35\left(A_{p, b} \rho \ddot{x}+g_{\text {env }}\right)
$$

The described optimisation algorithm is further illustrated in the following pseudo-code: 


\subsection{Columns and bracing optimisation}

Once the floor system optimisation step is completed, the next step is to compute the optimal cross-sectional area for columns and bracing members. As mentioned in section 3.4, by modelling each beam as pin-jointed enabled us to derive the design effects (shear, bending and deflection) by only considering the set of loading directly applied to the beam itself, therefore allowing us to use closed-form expressions - i.e. Eqs. $(4,10)$ and $(11)$ - to derive such reactions and displacements. Conversely, to determine the design (axial reaction) effects for each column and bracing member, the structural frame needs to be analysed in its entirety, therefore a numerical method of analysis becomes necessary. Based on the given geometrical and topological input parameters, a threedimensional model of the frame can be generated, and a linear-elastic analysis performed via Direct Stiffness Method (DSM) [50]. The standard implementation of the DSM requires an initial list of nodal coordinates (indicated with $\mathbf{p}$ in the following section) and a connectivity list storing information on the way beams, columns and bracing are connected to each other.

\subsubsection{Generating node list and connectivity list}

Reminding that primary and secondary structural grid directions coincide, respectively, with the global $x$ and $y$ directions (see Figure 1), a vector of global nodal coordinates $\bar{p}$ can be derived for each node as follows:

$$
\bar{p}_{i, j, k}=\left[\begin{array}{c}
p_{x} \\
p_{y} \\
p_{z}
\end{array}\right]=\left[\begin{array}{c}
L_{x} i \\
L_{y} j \\
H_{\text {floor }} k
\end{array}\right] \text { where: }\left\{\begin{array}{l}
i=0 \ldots n_{x} \\
j=0 \ldots n_{y} \\
k=0 \ldots n_{\text {floor }}
\end{array}\right.
$$

If the three-dimensional array containing the nodal coordinates $\bar{p}_{i, j, k}$ is generated according to the following pseudo-code for instance:

for $k$ in range 0 to $n_{\text {floor }}$ :

for $j$ in range 0 to $n_{y}$ :

for $i$ in range 0 to $n_{x}$ :

compute $\bar{p}_{i, j, k}$ as from Eq.

then, the array can be converted into a node list:

$$
\mathbf{p}=\left\{\bar{p}_{0} \ldots \bar{p}_{a} \ldots \bar{p}_{\left[\left(n_{x}+1\right)\left(n_{y}+1\right)\left(n_{\text {floor }}+1\right)-1\right]}\right\}
$$

in which the generic $\bar{p}_{a}$ vector-node corresponds to the $\bar{p}_{i, j, k}$ node according to the following equivalence between indexes:

$$
a(i, j, k)=i+k\left(n_{x}+1\right)\left(n_{y}+1\right)+j\left(n_{x}+1\right)
$$

The equivalence above will then be used to generate connectivity lists, in which, the generic item $\left\{a_{1}, a_{2}\right\}$, storing the indexes of each (column, beam and bracing) element's start-node (1) and 
end-node (2), will be obtained as follows:

$$
a_{1}=a(i, j, k) \rightarrow a_{2}=a(i+1, j, k)
$$

Eq. (17) applies to all primary beam-elements, while the following rule is used to generate the connectivity indexes of secondary beam-elements:

$$
a_{1}=a(i, j, k) \rightarrow a_{2}=a(i, j+1, k)
$$

and finally, the indexes of each columns' start/end-node:

$$
a_{1}=a(i, j, k) \rightarrow a_{2}=a(i, j, k+1)
$$

In this study it is assumed that diagonal bracing are able to withstand only tensile forces, ${ }^{5}$ two different rules are required for generating the bracing-element connectivity list in each global ( $x$ and $y$ ) direction: if the load combination under analysis involves horizontal (i.e. wind) loads directed toward $x$ or $y$, then:

$$
\begin{aligned}
& a_{1}=a(i, j, k) \rightarrow a_{2}=a(i+1, j, k+1) \\
& a_{1}=a(i, j, k) \rightarrow a_{2}=a(i, j+1, k+1)
\end{aligned}
$$

The first of Eqs. (20) applies for bracing-elements aligned to the $(x, z)$ global plane, while the second Eq. applies for bracing-elements parallel to the $(y, z)$ plane. For DSM analysis cases involving wind loads acting in the opposite direction to $x$ or $y$, the following rules apply instead:

$$
\begin{aligned}
& a_{1}=a(i, j, k) \rightarrow a_{2}=a(i-1, j, k+1) \\
& a_{1}=a(i, j, k) \rightarrow a_{2}=a(i, j-1, k+1)
\end{aligned}
$$

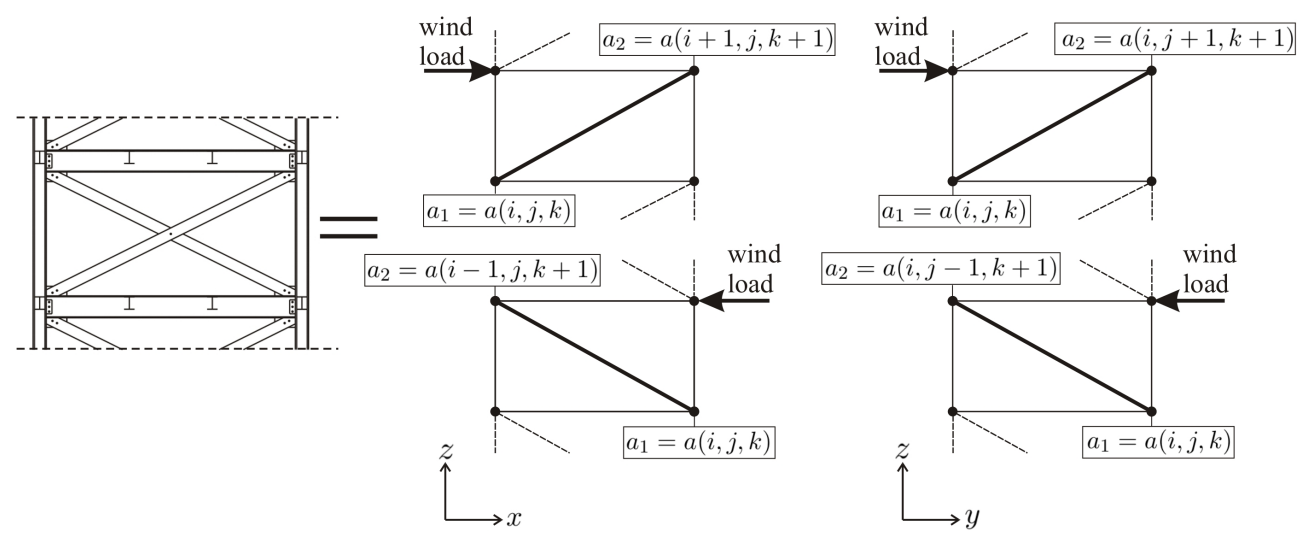

Figure 5: the start/end-nodes $\left(a_{1}, a_{2}\right)$ of bracing-element are selected for each load analysis case, according to the wind load direction and global plane orientation (i.e. either $(x, z)$ or $(y, z))$.

\footnotetext{
${ }^{5}$ A common feature in 'simple' frame construction.
} 
Again, the first of Eqs. (21) is referring to bracing-elements parallel to the $(x, z)$ global plane, while the second Eq. is for bracing-elements aligned to the $(y, z)$ plane. Figure 5 provides a graphical representation of the above-mentioned rules. Unlike for beams and columns, whose geometry and topology can be fully derived from the array of $\bar{p}_{i, j, k}$ nodes, the start-node and orientation plane of each bracing-element must be explicitly given. Such information are provided as input parameters via the list $\mathbf{b}$ (see section 3.1) which contains a series of three-item lists of the kind:

$$
b=\{j, i, \mathrm{~b}\}
$$

Such lists are user-provided, based on structural (or architectural) design considerations. In particular, the first and second items inside $b$ are the $j$ and $i$ indexes to insert into Eq. (16) in order to obtain the index, $a_{1}$, of the diagonals' start-node. The integers $j$ and $i$ essentially represent the 'row' and 'column', respectively, of the structural grid layout on the horizontal $(x, y)$ plane. The third item, b, in Eq. (22) is a binary variable: for $\mathrm{b}=\mathrm{x}$, the bracing is assumed to be oriented parallel to the $(x, z)$ plane, hence its end-node index, $a_{2}$, will be derived from the firsts of Eqs. (20, $21)$; for $\mathrm{b}=\mathrm{y}$, the bracing is assumed to be parallel to the $(y, z)$ plane, therefore its end-node index is obtained from the seconds of Eqs. $(20,21)$.

Secondary beams not directly connected to columns are not included in the three-dimensional frame model, as they have no influence on the overall stability of the frame. The additional selfweight generated by those beams is however included in the analysis, as illustrated in the next section. Lastly: the contribution to the frame lateral stiffness and stability provided by the floor slabs (and/or horizontal floor bracing) is taken into account by introducing rectangular membraneelements [51] having corner nodes' indexes $\left\{a_{1}, a_{2}, a_{3}, a_{4}\right\}$ :

$$
a_{1}=a(i, j, k) \rightarrow\left\{\begin{array}{l}
a_{2}=a(i+1, j, k) \\
a_{3}=a(i+1, j+1, k) \\
a_{4}=a(i, j+1, k)
\end{array}\right.
$$

\subsubsection{Matrix structural analyses}

The node list and connectivity lists determined so far are then used to compute the stiffness matrix of each element, and eventually assembling them into a global stiffness matrix, i.e. a square matrix with row and column size $=3(n x+1)(n y+1)\left(n_{\text {floor }}+1\right)$ in our case. After a few steps, involving operations of matrix sorting and partitioning, the DSM leads to the following subsystem of linear Equations:

$$
\mathbf{f}=\mathbf{K} \mathbf{x}
$$

in which: $\mathbf{K}$ is a square matrix having row (and column) size $=3(n x+1)(n y+1) n_{\text {floor }}$ in our case; $\mathbf{x}$ is the vector-list of unknown nodal displacements, and $\mathbf{f}$ is the vector-list of applied nodal forces, whose entries are filled by the vector components of each point load $\bar{P}_{a}=\left[P_{a, x}, P_{a, y}, P_{a, z}\right]^{\top}$ (i.e. the point load applied to each $\bar{p}_{a}$ node). Magnitude and orientation of the applied point load will 
depend on the node location and load combination under analysis. One permanent load case $(G)$, one imposed floor load case $(Q)$ and eight wind load cases $\left(W_{w}\right)$ are considered in here. These ten loading cases are combined together, thus obtaining a total of 17 load combinations:

$$
\begin{gathered}
G+Q \\
G+W_{w} \quad \text { where: } w=0 \ldots 7 \\
G+Q+W_{w} \quad \text { where: } w=0 \ldots 7
\end{gathered}
$$

For the load combination involving only gravity loads, i.e. Eq. (25), the horizontal components of $\bar{P}_{a}$ are both null, and the vertical component is taken as follows. For internal nodes:

$$
P_{a, z}=-\left(2 V_{E d}+A_{c} H_{\text {floor }} \rho \ddot{x}\right)
$$

where $A_{c}$ is the column's cross-sectional area. It should be noted that the shear force $V_{E d}$ as from Eq. (11), is function of $P_{d}$ and $U_{d^{*}}$, which in turn, must be computed by inserting into Eqs. $(8,9)$ the (previously fund) optimal secondary and primary beams' area sections, $A_{s, b}$ and $A_{p, b}$ respectively.

For edge nodes surrounded by primary beams, Eq. (28) still applies, but the design shear force $V_{E d}$ must be derived from Eqs. $(12,13)$ instead.

For edge nodes surrounded by secondary beams, the value of $V_{E d}$ to insert into Eq. (28) is that provided by the second of Eqs. (4), in which $U_{d}$ is replaced by $U_{d, e n v}$ as from Eq. (7).

For corner nodes, the value of $V_{E d}$ to insert into Eq. (28) is taken as follows:

$$
V_{E d}=\frac{P_{d, e n v} n_{s, b}+U_{d^{*}, e n v} L_{x}+U_{d, e n v} L_{y}}{2}
$$

with $P_{d, e n v}, U_{d^{*}, e n v}$ and $U_{d, e n v}$ as given in Eqs. $(12,13)$ and $(7)$ respectively.

For load combinations involving wind loads and gravity loads, two distinct situations arises: if only permanent loads, $G$, are taken into account (i.e. Eqs. (26)), the point loads' vertical component $P_{a, z}$ can still be computed according to Eqs. (28) to (29) however, the value of $q_{\text {floor }}$ required to derive $V_{E d}$ must be set to zero. If the load combinations involve both permanent and variable loads (i.e. Eqs. (27)), the user-provided input value of $q_{\text {floor }}$ is used for calculations. Further to this, for load combinations involving wind loads, the horizontal components of $\bar{P}_{a}$ will be function of the wind load orientation and node position. A horizontal design wind pressure $1.5 q_{\text {wind }}$, is assumed to act on the external windward walls for each load case $W_{w}$.

The pressure value $1.5 q_{\text {wind }}$ can be therefore converted into an equivalent horizontal point load representing the horizontal components $\left[P_{a, x}, P_{a, y}\right]^{\top}$ of $\bar{P}_{a}$, and applied only to those edge nodes interested by the wind load case under consideration, as shown in Figure 6. For instance, for load 


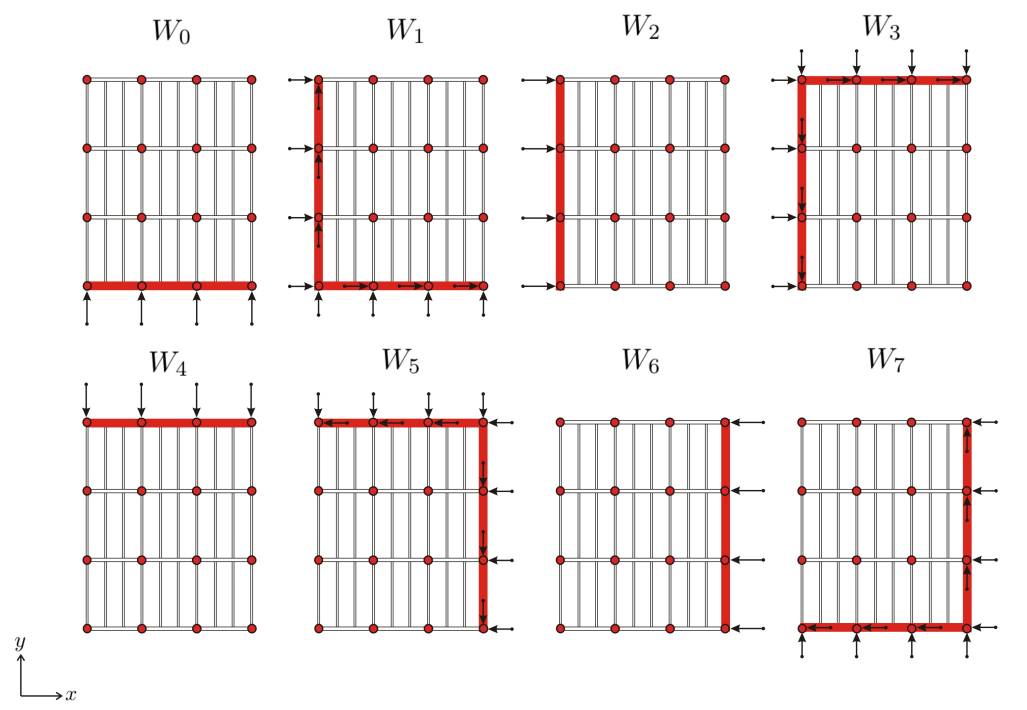

Figure 6: the bold line indicates the windward walls interested by wind action for each $W_{w}$ load case. The arrow indicates the horizontal components of the equivalent (wind) point load.

case $W_{0}$ the wind pressure is assumed to act in the same direction and verse of the $y$ global direction (Figure 6) and therefore:

$$
\left[\begin{array}{c}
P_{a, x} \\
P_{a, y}
\end{array}\right]=\left[\begin{array}{c}
0 \\
1.5 q_{\text {wind }} L_{x} H_{\text {floor }}
\end{array}\right]
$$

The wind load magnitude is assumed constant for all wind load cases $W_{w}$, while the wind direction is rotated at increments of 45 degrees for the remaining cases (i.e. for $w=1 \ldots 7$ ) as shown in Figure 7. A general equation, to compute the horizontal components of $\bar{P}_{a}$ for all wind load cases, can be formulated by aid of a rotation matrix:

$$
\left[\begin{array}{c}
P_{a, x} \\
P_{a, y}
\end{array}\right]=\left[\begin{array}{cc}
\cos \left(\frac{\pi w}{4}\right) & -\sin \left(\frac{\pi w}{4}\right) \\
\sin \left(\frac{\pi w}{4}\right) & \cos \left(\frac{\pi w}{4}\right)
\end{array}\right] \cdot\left[\begin{array}{c}
0 \\
1.5 q_{\text {wind }} A_{\text {wall }}
\end{array}\right]
$$

where: $w=0 \ldots 7$

For windward walls parallel to the global $(x, z)$ plane, the (tributary) external wall area, $A_{\text {wall }}$, will be taken as equal to $L_{x} H_{\text {floor }}$, while for walls aligned to the $(y, z)$ plane: $A_{\text {wall }}=L_{y} H_{\text {floor }}$. Further distinctions (not described in here for the sake of brevity) have to be made when deriving $A_{\text {wall }}$ for nodes at the edges and at corners of the windward walls.

The effect of geometric imperfections on the global stability of the frame is taken into account during analyses by modelling the frame out-of-plumb as shown in Figure 8. The generic node $\bar{p}=\left[p_{x}, p_{y}, p_{z}\right]^{\top}$ as from Eq. (14), is translated horizontally toward the wind-load direction by $\phi p_{z}$ amount. A value of 'initial sway imperfection' $\phi$ [47] between zero and 1/200 rad can be set by the user. 


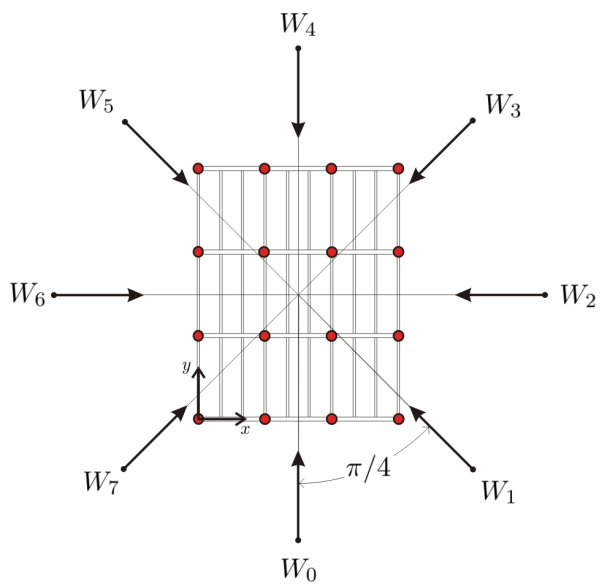

Figure 7: The wind load is accounted for in the analysis by considering eight different wind directions, at increments of 45 degrees each.

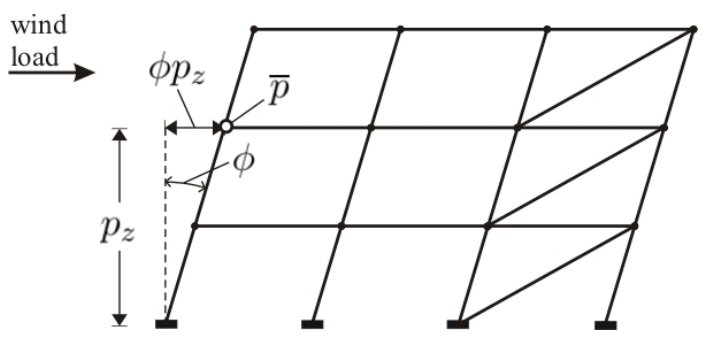

Figure 8: Initial sway imperfection of the frame geometry. Figure adapted from [47].

\subsubsection{Local Search procedure}

For each of the 17 load combinations described in the previous section, the system of Eq. (24) is solved for $\mathbf{x}$ :

$$
\mathbf{x}=\mathbf{K}^{-1} \mathbf{f}
$$

which provides the updated position of each $\bar{p}_{a}$ node, therefore allowing us to compute the elements' shortening/elongation, which in turn enables to derive the internal compressive force of each column $\left(N_{C}\right)$ and tensile force of each bracing $\left(N_{B}\right)$, for each load combination. A design compressive force, $N_{C, E d}$ is therefore obtained for every column, taken as the maximum $N_{C}$ value:

$$
N_{C, E d}=\max \left\{N_{C, 1} \ldots N_{C, 17}\right\}
$$

as well, a design tensile force for every bracing is obtained:

$$
N_{B, E d}=\max \left\{\left|N_{B, 1}\right| \ldots\left|N_{B, 17}\right|\right\}
$$

As for beams, each column and bracing is then verified against compressive buckling and tensile 
stress according to design standard procedures [47]:

$$
\frac{N_{C, E d}}{N_{b, R d}}-1 \leq 0 \quad ; \quad \frac{N_{B, E d}}{N_{t, R d}}-1 \leq 0
$$

where $N_{b, R d}$ is the column's buckling resistance, and $N_{t, R d}$ the tensile resistance of the bracing, both computed based on cross-section properties of available profiles. The exact same Sequential Search procedure, described in section 3.4.2, therefore applies in here to minimise the section area (that is to say, the mass) of each individual column and bracing.

Notwithstanding, because of the (eventual) statical indeterminacy of the structural frame system (see Figure 9), the value of reaction forces $N_{C, E d}$ and $N_{B, E d}-$ upon which optimal column and bracing area sections are derived - are sensitive to the axial stiffness terms $(E A) / L$ initially set to initialise the DSM analyses.

A Local Search procedure is thus employed to get round this problem. First, a set of DSM analyses (one for each load combination) is launched. The axial stiffness terms specified for this first set of DSM analyses, and required to build the elements' stiffness matrices, it is arbitrarily piked based on a list $t$ of available sections. At analyses completion, an 'optimal' area section is derived via Sequential Search for each column and bracing (Eqs. (35)). At this point, a second set of DSM analyses can be run, but considering, this time, the previously found 'optimal' area sections when assembling the elements' stiffness matrix. The 'optimal' area section values, obtained at completion of this second run of analyses, will be closer to the actual optimal values compared to those obtained at completion of the first run of analyses. In more general terms: the (DSM plus Sequential Search) analyses at the $n^{\text {th }}$ step are initialised by considering the cross-sectional areas obtained as output of the $(n-1)^{\text {th }}$ step. The described iterative procedure is eventually stopped according to a given convergence criteria, as for instance, when the difference between outputs, obtained from two consecutive steps, is smaller than a given threshold value, and thus a near optimal solution is achieved. Indicating with $T_{\text {mass }}$ the total mass of the steel frame, the optimal design is assumed to be found in here at fulfilment of the following inequality:

$$
\left|T_{\text {mass }}^{n}-T_{\text {mass }}^{n-1}\right| \leq \gamma T_{\text {mass }}^{n-1}
$$

with $\gamma \in[0,1]$. As shown in section 4.2, for $\gamma=0.001$, two to three iterations are usually sufficient for the optimisation algorithm to meet the convergence criteria stated above.

\subsection{Embodied Carbon estimation}

The optimal cross-sectional area of every (beam, column, bracing) member so found is then multiplied with the corresponding member's length, therefore obtaining the overall structural steel volume, hence mass. It must be noted that such mass value, outcome of the optimisation process, represents a lower-bound estimate of the minimum amount of steel that could be possibly used for the frame geometry at hand. 
(a)

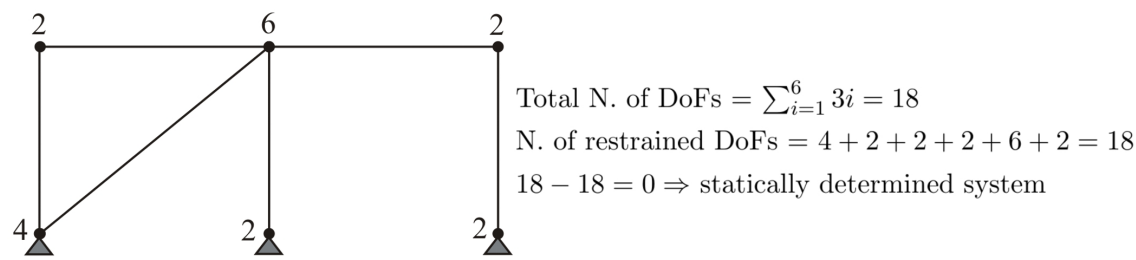

(b)

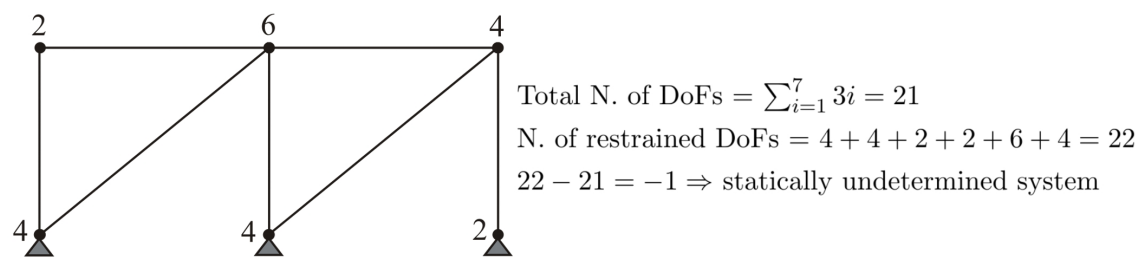

Figure 9: the degree of indeterminacy in 'simple' frame constructions is mostly dependent on the number and position of its bracing. The statically determined frame (a) becomes statically undetermined when an additional brace is introduced. The number near each node indicates the N. of restrained DoFs at that node.

To take into account uncertainties linked to the 'degree' of rationalisation of cross-sections design, the overall structural steel mass of a 'non-optimised' frame is also computed (see Figure 10). The non-optimised frame design is a geometrically similar frame in which a uniform cross-sectional area is assumed for columns and bracing that are vertically aligned, ad it is taken as the maximum area section within that line of columns or bracing. Similarly, all beams within each floor are assumed to have the maximum cross-sectional area occurring at that floor. The underpinning idea of computing a mass value for the non-optimised frame is to derive an upper-bound value of steel mass that would result if a rationalisation-driven approach were to be taken by structural designers when dimensioning the members' cross-sections.

\subsubsection{Montecarlo analysis}

To avoid misleading the decision-maker with very definite numbers, both structural mass and embodied carbon coefficients are considered along with their uncertainty through Montecarlo simulation [19]. Based on the upper/lower bound values of steel mass obtained so far, an estimation of the embodied carbon is then carried out by first sampling 5000 random values of steel mass from a uniform distribution bounded by the upper/lower bound values of steel mass previously obtained. Each mass sample is then multiplied with an embodied carbon coefficient value, equally randomly picked from a Gaussian distribution based on the EC parameters of mean and standard deviation, $\sigma_{E C}$ and $\mu_{E C}$. The default values for such parameters are taken from [4], which is a recent analysis of embodied carbon coefficients used and published in scientific literature. More specifically, we have taken as default values the mean and standard deviation from the dataset referred above but the tool allows the user to input different values to reflect the peculiarities of the specific context being examined (see section 3.1).

Based on the sample population of EC values, an embodied carbon estimation of the steel frame is eventually outputted to the user in terms of mean and standard deviation values, together with an histogram showing the probability density function of the EC frame sample population (see Figure 


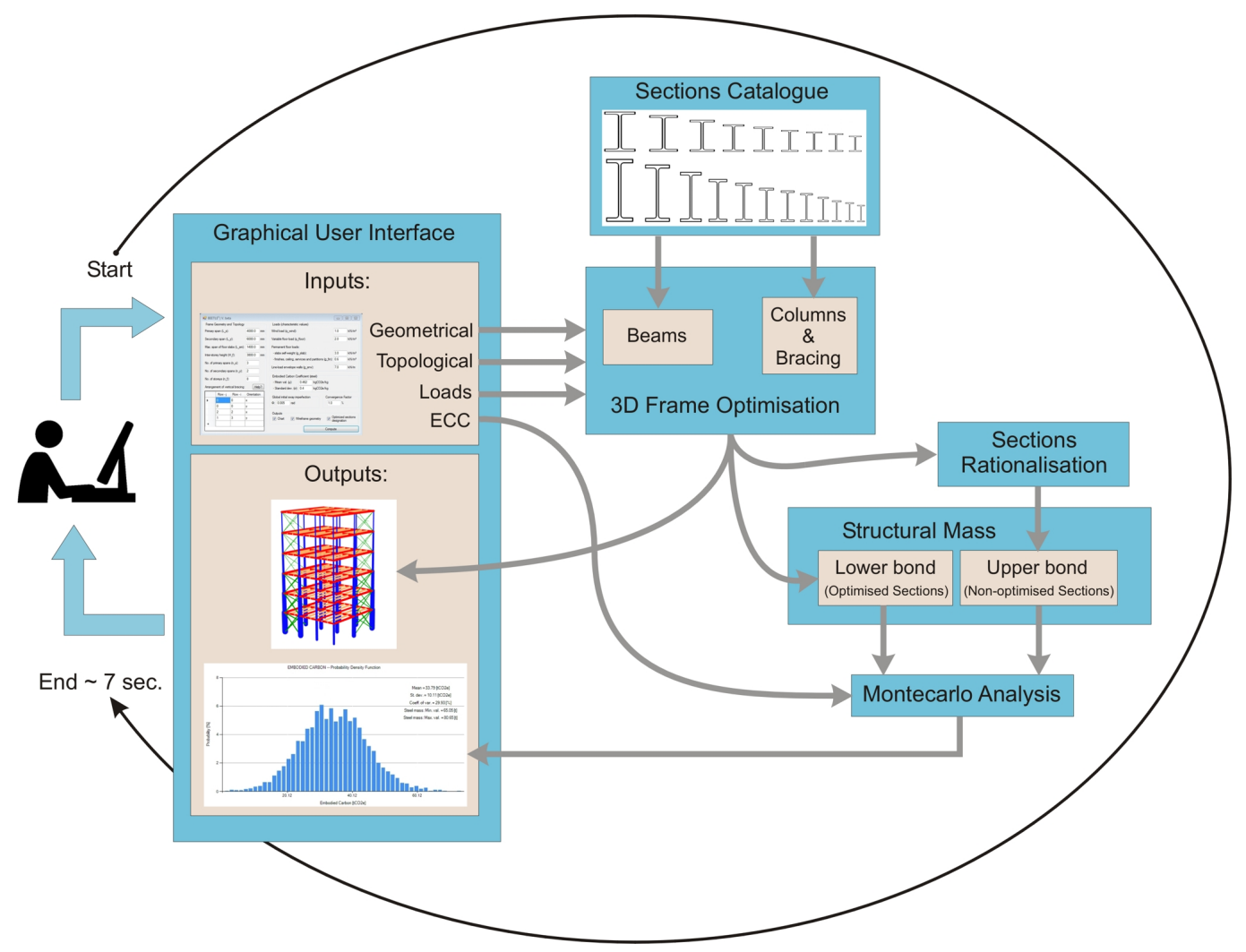

Figure 10: Flow-chart of the computational tool.

11). A flow-chart of the algorithms described so far is shown in Figure 10. The total time for a full cycle is in the order of few seconds.

\subsection{Tool's limitations}

From the theory provided so far, it should be clear that the parametric-based tool is limited to designs of steel frames having a rectangular layout plan, with constant span lengths $\left(L_{x}\right.$ and $\left.L_{y}\right)$, yet, an arbitrary number of storeys can indeed be set as input parameter. Technically speaking, the algorithm's core functions can be easily extended to handle more geometrically complex frame geometries. This would require to extend the domain of inputs. However the parameters currently considered are believed to be those which influence the most embodied carbon [52]. Alternatively, an import function may be added, i.e. to allow input loading of 3D frame geometries preliminary modelled via third-party CAD software, therefore increasing the tool's capabilities, but perhaps, making it more clumsy to use for designs exploration task.

A further clarification is made with regard to the (Eurocode-based) structural verification equations taken into account for this study. In design practice, Eqs. (3, 35) are usually checked for during the initial task of preliminary members sizing, whilst additional verifications not considered in here - i.e. concerning the design of connections - are then carried out as the structural design develops further, and additional refinements of the members' cross-section may take place. It is worth reminding that the ultimate goal of this tool is not to generate detailed structural design 


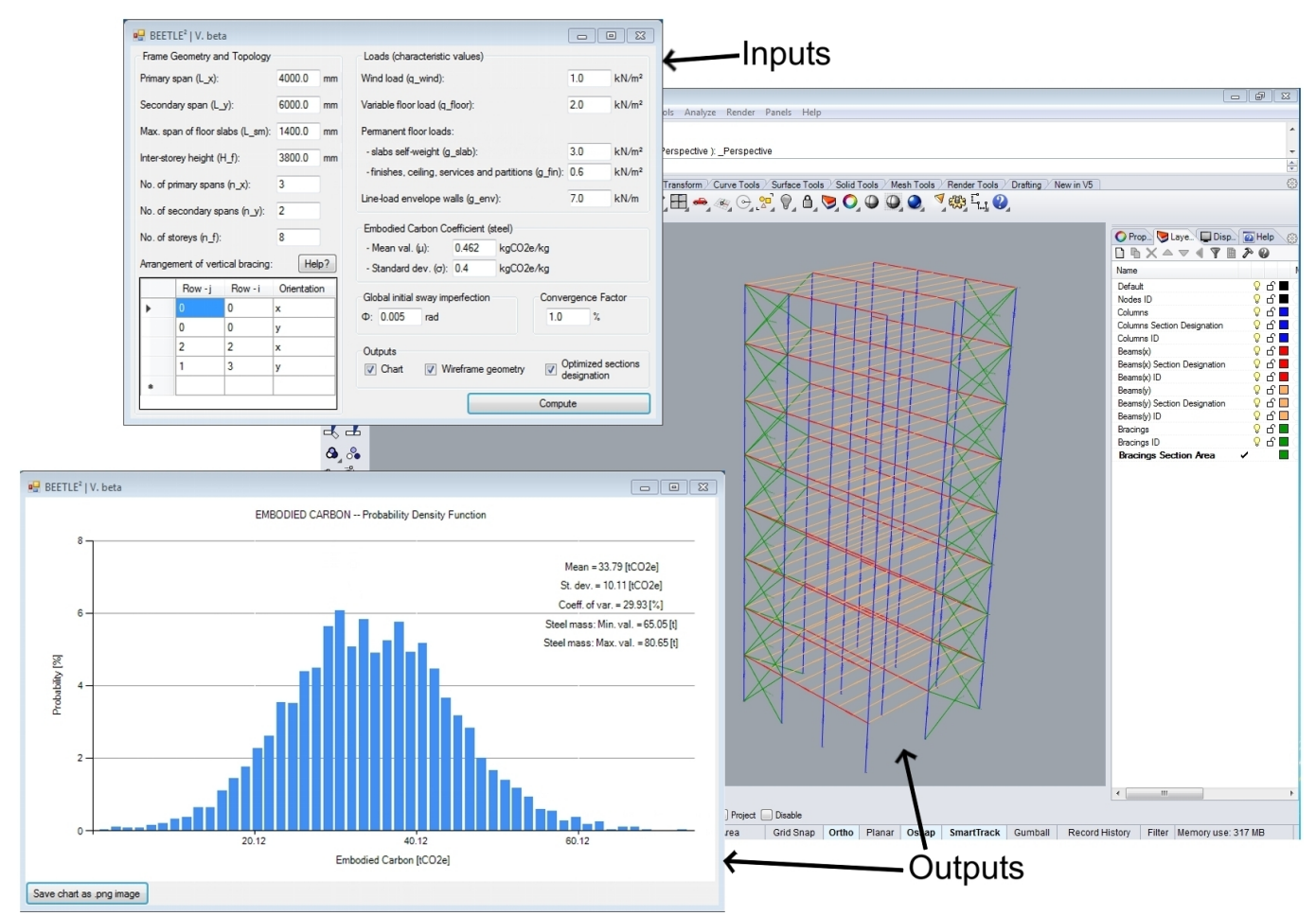

Figure 11: Tool implementation as a Rhinoceros plug-in.

specifications. Rather, it should be seen as a decision-making tool to help practitioners assessing, in a reasonably quick amount of time, alternative frame geometries, based on their relative embodied carbon output.

The described methodology can be translated to other structural materials. However, the mathematical underpinning of the problem, the exact methods to determine optimal structures, and the material-specific constraints clearly vary from case-to-case. As such, while the tool is suited to be extended to timber and reinforced concrete, such implementation will require the same expert knowledge (e.g. design codes, professional experience) and dedicated time for software design and implementation.

\section{Calculations}

\subsection{Implementation}

To allow effective usage of the described tool, a script written in IronPython 2.7, has been developed to run inside Rhinoceros 5 (Windows version, Service Release 12), which is a CAD software widely used by design practitioners. The script is distributed as a Rhinoceros plug-in application (.rhp file) which can be loaded and executed via Rhinoceros command line interface. At execution completion, output results are returned in a graph format. A 3D wire-frame model of the steel structure is also generated and displayed in the Rhinoceros main viewports (see Figure 11). The 3D model can then be used as a basis for further geometrical modelling within the same 
Rhinoceros environment, or exported to dedicated structural analysis software. The tool has been named BEETLE ${ }^{2}$ which stands for Built Environment Tool for Low Environmental Externalities and it has been made freely available for public use through the Food4Rhino platform [53].

The list of available cross-section profiles has been implemented based on the Eurocode Blue Book catalogue [49], limited to Universal Beam and Universal Column type-profiles, for beam and column members respectively, while flat section profiles are considered for bracing members. At analysis completion, the optimised cross-section designation of each structural member can be also shown in the viewports.

To enable for fast running times, the script relies on dedicated numerical computing libraries to solve the system of linear Eqs. (32). Two implementation versions have been developed: one using NumPy [54] and a second one using Math.NET Numerics [55]. More details on the tool's running times are provided in section 4.4 .

\subsection{Validation}

The Direct Stiffness Method of analysis implemented within the tool was extensively validated by checking the output results, in terms of nodal displacements and reaction forces, against results obtained via the structural analysis software SAP2000, v18.2.0. Excluding (negligible) numerical rounding off, the two outputs were perfectly matched.

A steel frame example is considered in here to demonstrate how the implemented Local Search algorithm, described in section 3.5.3, converges to the same exact solution regardless of the initial cross-sectional area value, set into $(E A) / L$ when assembling the elements' stiffness matrix for the first analysis step. The example frame geometry is shown in Figure 12, whilst the prescribed input parameters are given as follows: $L_{x}=4000 \mathrm{~mm} ; L_{y}=6500 \mathrm{~mm} ; L_{\text {slab, } \max }=2500 \mathrm{~mm}$; $H_{\text {floor }}=4000 \mathrm{~mm} ; n_{x}=5 ; n_{y}=3 ; n_{\text {floor }}=8 ; q_{\text {wind }}=3 \mathrm{kN} / \mathrm{m}^{2} ; q_{\text {floor }}=4 \mathrm{kN} / \mathrm{m}^{2} ; g_{\text {env }}=8$ $\mathrm{kN} / \mathrm{m} ; g_{\text {slab }}=5 \mathrm{kN} / \mathrm{m}^{2} ; g_{\text {fin }}=0.6 \mathrm{kN} / \mathrm{m}^{2}$. The system of bracing is set via input list $\mathbf{b}$ as follows (see section 3.5.1):

$$
\mathbf{b}=\{\{1,1, \mathrm{x}\},\{1,1, \mathrm{y}\},\{1,2, \mathrm{y}\},\{2,1, \mathrm{x}\},\{0,4, \mathrm{x}\},\{3,4, \mathrm{x}\},\{1,5, \mathrm{y}\}\}
$$

A single cross-sectional value of $1000 \mathrm{~mm}^{2}$ was set to all columns and bracings for the first analysis step (i.e. iteration count $=0$ ). The same search was repeated seven more times, increasing the initial section area at increments of $1000 \mathrm{~mm}^{2}$ for each run. All analyses were stopped when the total mass at the $n^{\text {th }}$ step was found to be $\pm 0.1 \%$ of the mass obtained at the $(n-1)^{\text {th }}$ step.

As from Table 1, this occurred at iteration N. 3 (i.e. fourth analysis step) for all nine runs. The total steel masses reported in Table 1 do not include the beams' masses as these are pre-computed in a previous optimisation task, hence their total amount remains constant throughout the iterative procedure that follows. The final optimisation output is shown in Figure 13. 

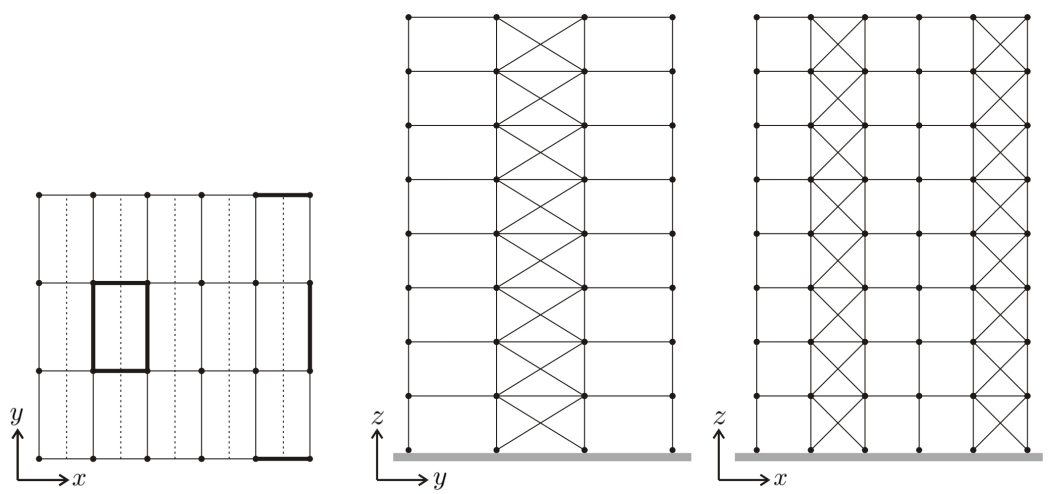

Figure 12: frame geometry considered for the Local Search validation test described in section 4.2. With reference to the layout plan shown on the left: bold lines indicate the bracing position, while the dashed lines indicate secondary beams not directly connected to columns.
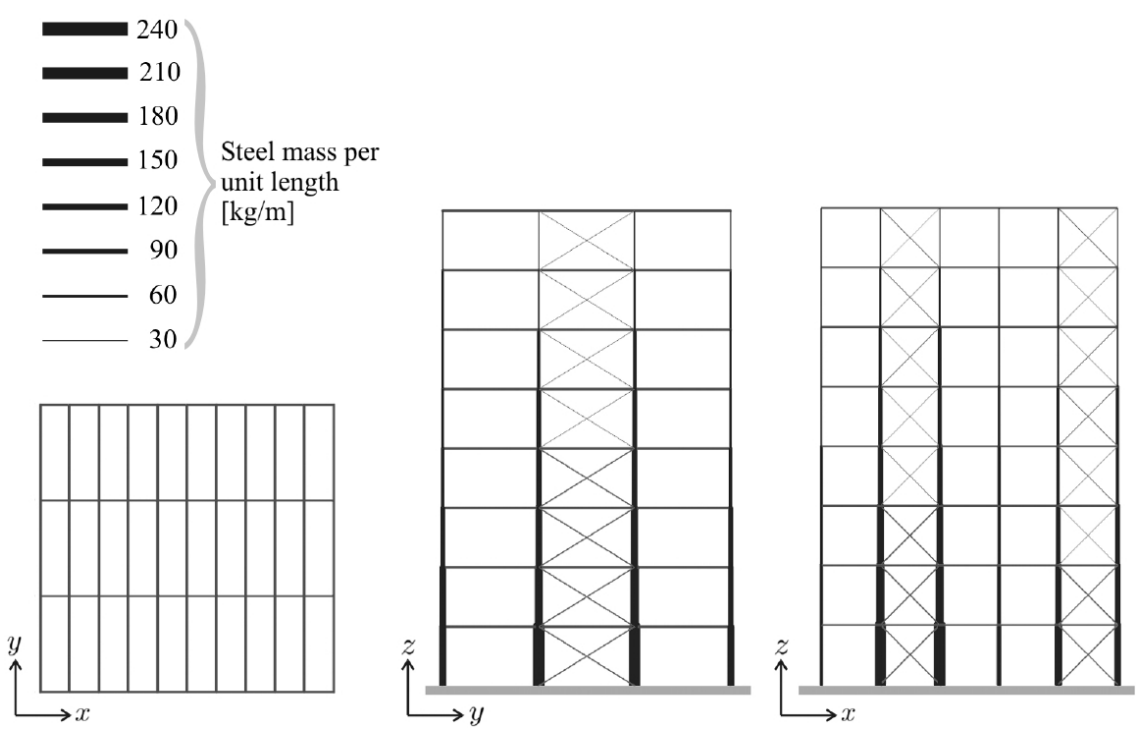

Figure 13: Optimised steel frame cross-section.

\subsection{Enforcing structurally-sound bracing layouts}

By looking at Table 1, it can be observed that the implemented Local Search algorithm converges very quickly. In reality, the convergence rate is very sensitive to the bracing arrangement in the plan layout of the building frame. Let consider, as an example, the same frame model used in section 4.2, but arranging its bracing layout along two vertical planes only, as shown in Figure 14-a. As it can be seen from Table 2, the algorithms required up to 7 iterations prior to converge to a solution. Indeed, the bracing layout chosen for this test does not provide any torsional stiffness to the frame, and although a solution was found, such output it is of little practical use, as the solved system of Eqs. (24) is based on an ill-conditioned matrix K. From a physical point of view, this corresponds to a steel frame that would collapse under the effect of wind-induced torque.

Structural design practitioners are obviously aware of what a structurally-sound braced frame layout looks like, nonetheless a series of logical statements have been included in the script to enforce 
Table 1: convergence of the Local Search algorithm described in section 3.5.3. The frame geometry shown in Figure 12 is optimised by assuming a different cross-sectional value, of columns and bracings, for each analysis run. All analyses converged to the same mass result (62.4390 ton), regardless of the initial section area.

\begin{tabular}{ccccccccc}
\hline Iteration & \multicolumn{8}{c}{ Total steel mass of columns + bracings [ton] } \\
count & $1^{\text {st }}$ run & $2^{\text {nd }}$ run & $3^{\text {rd }}$ run & $4^{\text {th }}$ run & $5^{\text {th }}$ run & $6^{\text {th }}$ run & $7^{\text {th }}$ run & $8^{\text {th }}$ run \\
\hline 0 & 11.7391 & 23.4782 & 35.2174 & 46.9565 & 58.6956 & 70.4347 & 82.1739 & 93.9130 \\
1 & 62.8599 & 62.8579 & 62.8559 & 62.8541 & 62.8522 & 62.8504 & 62.8486 & 62.8468 \\
2 & 62.4837 & 62.4837 & 62.4837 & 62.4837 & 62.4306 & 62.3776 & 62.3776 & 62.3776 \\
3 & 62.4390 & 62.4390 & 62.4390 & 62.4390 & 62.4390 & 62.4390 & 62.4390 & 62.4390 \\
\hline
\end{tabular}

(a)

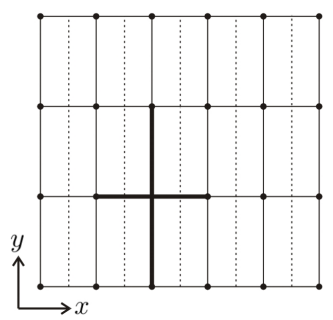

(b)
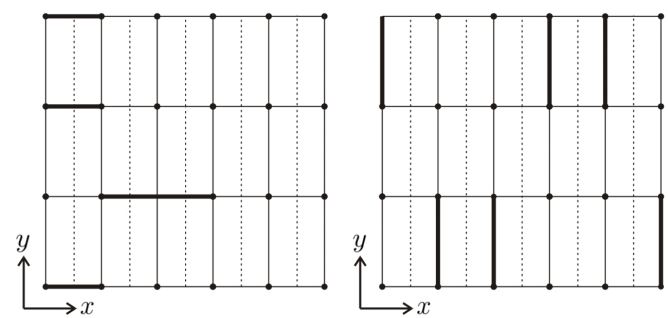

Figure 14: Unstable frame layouts. The bold lines indicate the bracing position. (a) the steel frame lacks of torsional stiffness. (b) the steel frame lacks of lateral stiffness along the $y$ or $x$ direction.

'correct' inputting (see section 3.5.1) of the bracing list b. In particular: at least two bracings on two different $(\mathrm{x}, \mathrm{z})$ planes and two more bracings on two different $(\mathrm{y}, \mathrm{z})$ planes (i.e. four planes in total) must be given as input. In addition to prevent torsionally unstable frame designs, this also prevents the user to set all bracings aligned along the same ( $x$ or $y)$ direction, as shown in Figure 14-b, which again, would result in the frame behaving as a mechanism, with the matrix $\mathbf{K}$ becoming singular.

\subsection{Computing time}

In Figure 16-a is shown the time (in seconds) required to compute a solution for the frame example described in section 4.2, but setting a different number of storeys (ranging from 1 to 8 ) for each run. The model size for each run is expressed in terms of matrix size $\mathbf{K}$ and total number of

Table 2: the total number of required iterations is increased due to a 'poor' arrangement of the bracing layout (shown in Figure 14-a).

\begin{tabular}{cc}
\hline $\begin{array}{c}\text { Iteration } \\
\text { count }\end{array}$ & $\begin{array}{c}\text { Total steel mass of } \\
\text { columns }+ \text { bracings [ton] }\end{array}$ \\
\hline 0 & 58.506 \\
1 & 63.382 \\
2 & 85.612 \\
3 & 60.738 \\
4 & 61.145 \\
5 & 74.962 \\
6 & 61.599 \\
7 & 61.560 \\
\hline
\end{tabular}


(beam, column, bracing and rectangular-membrane) elements as shown in Table 3. Total number of iterations required for each run are also given in the same Table. An Hewlett-Packard computer desktop machine, running on a Intel(R) Core i5-4570 CPU, with 4007 MB of memory RAM, was used for analyses. As expected, the increase in computing time is related to the increase in size of the model. By looking at the seventh column of Table 3, it can be seen that computing times are also dependent on the total number of iterations required for the algorithm to converge. As shown in Figure 16-a, for the biggest model the algorithm took about 63 seconds (NumPy implementation) and less than 23 seconds (Math.NET implementation) to converge. This time-frame would not allow real-time user interaction, however we believe, it is reasonably fast to enable exploration of several alternative options at early design stage. The script implementation with Math.NET Numerics libraries is found to be $\approx 5$ times faster (on average) compared to the NumPy implementation.

Figure 16-b shows the computing times relative to the 8-storey frame example described in section 4.2, but considering this time six different bracing layouts (shown in Figure 15). It can be observed that run times values are $\approx 24$ seconds for bracing layouts I, III and V and $\approx 16$ seconds for bracing layouts II, IV and VI. This is explained by considering the number of iterations required for each example: frame examples I, III and V required three iterations to converge, whereas for frames II, IV and VI only two iterations were required.

\subsection{Application}

Figure 17 shows a typical output of the tool applied to the 8-storey frame example described in section 4.2. The input values for mean EC coefficient and standard deviation were set respectively to 0.462 and $0.326 \mathrm{kgCO}_{2 \mathrm{e}} / \mathrm{kg}$ [4]. Overall $(\mathrm{min} / \mathrm{max})$ steel mass values of 215 tonnes and 278 tonnes were obtained respectively for the optimised and non-optimised cross-section designs, which represents a carbon reduction potential of $22.6 \%$. Based on these domain values, a mean EC value of $113.5 \mathrm{tCO}_{2 \mathrm{e}}$ with standard deviation of $28.1 \mathrm{tCO}_{2 \mathrm{e}}$ were found for the steel frame example under description.
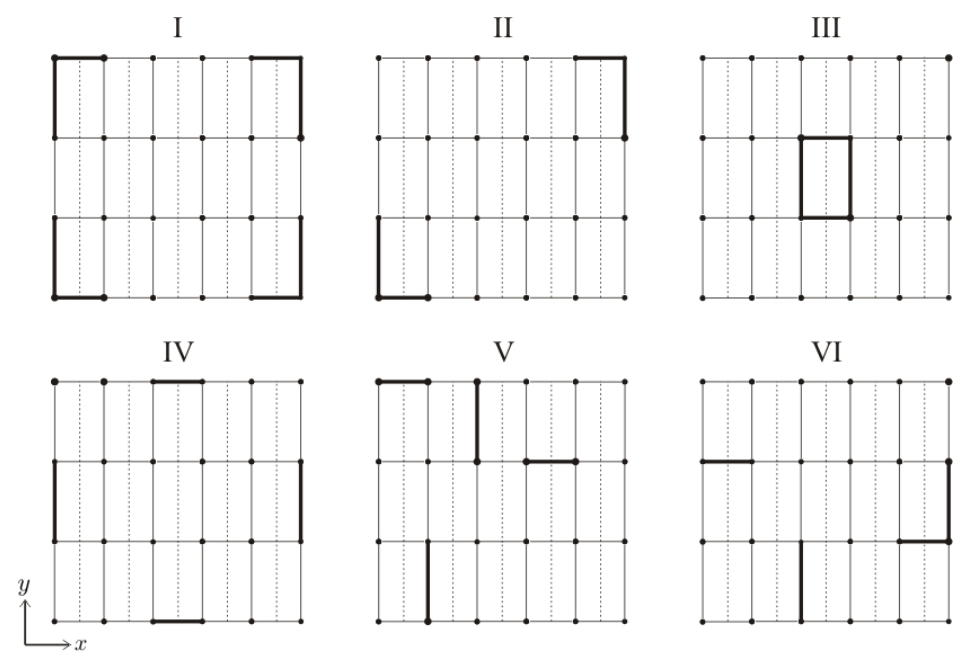

Figure 15: Bracing layouts used to assess the script's computing times (shown in Figure 16-b). 
(a)

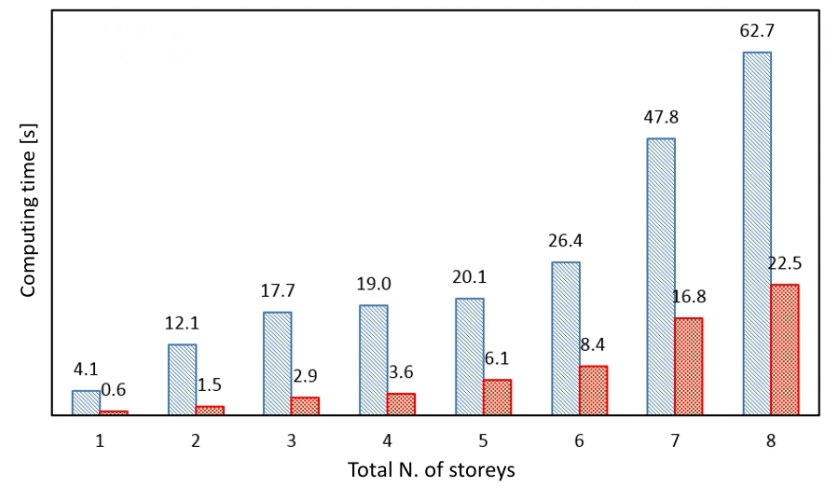

(b)

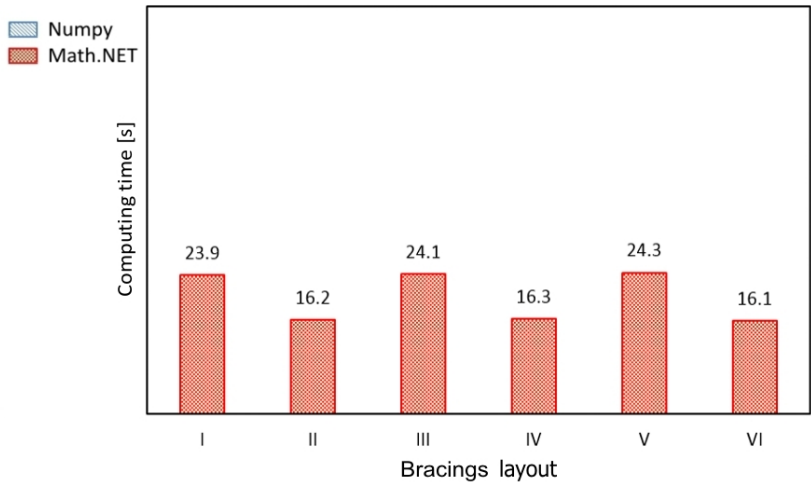

Figure 16: (a) computing time as function of size of the structural frame, measured in here in terms of number of storeys. Additional details for each frame geometry are given in Table 3. (b) computing time as function of the bracing layout (as shown in Figure 15).

Table 3: Size of frame geometries used to assess the script's computing times (shown in Figure 16-a). The layout plan considered for the frame geometries is that shown in Figure 12 (first on the left).

\begin{tabular}{|c|c|c|c|c|c|c|}
\hline \multirow{2}{*}{$\begin{array}{l}\text { Total N. } \\
\text { of storeys }\end{array}$} & \multirow{2}{*}{$\begin{array}{c}\text { Size of } \\
\text { matrix } \mathbf{K}\end{array}$} & \multicolumn{4}{|c|}{ Total N. of elements } & \multirow{2}{*}{$\begin{array}{c}\text { N. of } \\
\text { iterations }\end{array}$} \\
\hline & & columns & beams $^{\mathrm{a}}$ & bracings ${ }^{b}$ & membranes & \\
\hline 1 & $72 \times 72$ & 24 & 38 & 7 & 15 & 2 \\
\hline 2 & $144 \times 144$ & 48 & 76 & 14 & 30 & 3 \\
\hline 3 & $216 \times 216$ & 72 & 114 & 21 & 45 & 3 \\
\hline 4 & $288 \times 288$ & 96 & 152 & 28 & 60 & 2 \\
\hline 5 & $360 \times 360$ & 120 & 190 & 35 & 75 & 2 \\
\hline 6 & $432 \times 432$ & 144 & 228 & 42 & 90 & 2 \\
\hline 7 & $504 \times 504$ & 168 & 266 & 49 & 105 & 3 \\
\hline 8 & $576 \times 576$ & 192 & 304 & 56 & 120 & 3 \\
\hline
\end{tabular}

${ }^{\mathrm{a}}$ secondary beams not connected to columns are not included in the DSM analysis.

${ }^{b}$ only one element per cross-bracing is included in the DSM analysis (see Figure 5).

The implication of the results of our work are relevant to both theory and practice. From a theoretical perspective, the method developed for this research and the tool resulting out of it have brought together two disciplines which do not often communicate; structural engineering and optimisation and environmental and life cycle assessment. Often, indeed, structural engineers use dubious ECCs as a multiplier for the accurate mass value they have established in order to determine the 'sustainability' of a building. Similarly, environmental scientists use overly accurate results from LCAs as a multiplier for an average tonnage of construction materials which might not represent the case they are investigating. Our aim has therefore been that of increasing the accuracy, therefore the reliability, of both defining elements of a sustainable structure, that is, a lower -but realisticamount of the structural material used and a pertinent estimate of the embodied GHGs.

The implications to practice are equally significant. To best of the authors' knowledge, a tool such the one presented in this article does not exist -probably as a reflection of the two, often separated, communities described above. BEETLE ${ }^{2}$ is a freely available tool to professionals and practitioners which does not impose prerequisite knowledge to be used and it is therefore suited to the novice as well as the expert user. Being fully integrated with the widely used Rhinoceros, 


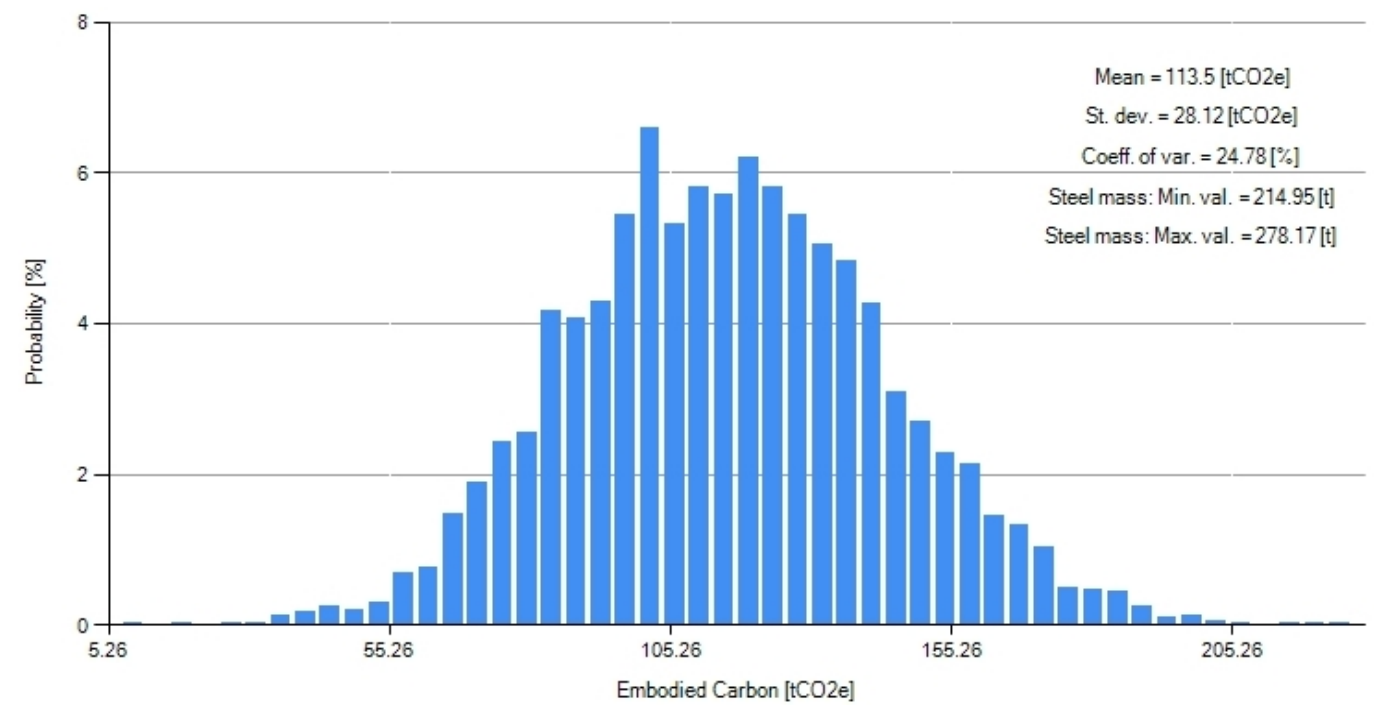

Figure 17: Probability density function of embodied carbon, based on the 8-storey frame example described in section 4.2 .

it allows for a great degree of inter-usability across systems, platforms, and professions. The extremely fast computational time and the few input parameters required enable structure-related sustainability decisions to be anticipated at a very early-stage in the building and structural design. As such, alternative designs can be considered when the opportunity for improvement is greatest and its impact on costs minimal.

\section{Conclusions}

The embodied carbon of a building represents a growing share of its life cycle emissions, and it is strongly driven by the choice of the materials used and their quantities. Steel is one of the construction materials with greatest environmental impacts and although approaches exist to design material-efficient structures they are seldom used in practice. This paper has addressed such problem with an aim of bridging the gap between academic research on structural optimisation and embodied carbon assessment and the needs of the construction industry. In particular, the present work has focussed on steel frames and the reason is twofold.

First, steel frames are widely used across a large number of built assets therefore ensuring a potentially large application of the findings from this research. Secondly, the steel industry is responsible for a quarter of the global $\mathrm{CO}_{2}$ emissions, and nearly half of all produced steel is used in construction.

The purpose of this work was to develop a user-friendly tool that could be used at early design stage to drive embodied carbon reduction when the possibility to do so is greatest. The aim was for the tool to be rooted in academic rigour but designed with practical use in mind to overcome most of the limitations of existing academic works in the area. The tool has been created to be utilised in Rhinoceros, a CAD software package widely used in the construction industry. Given 


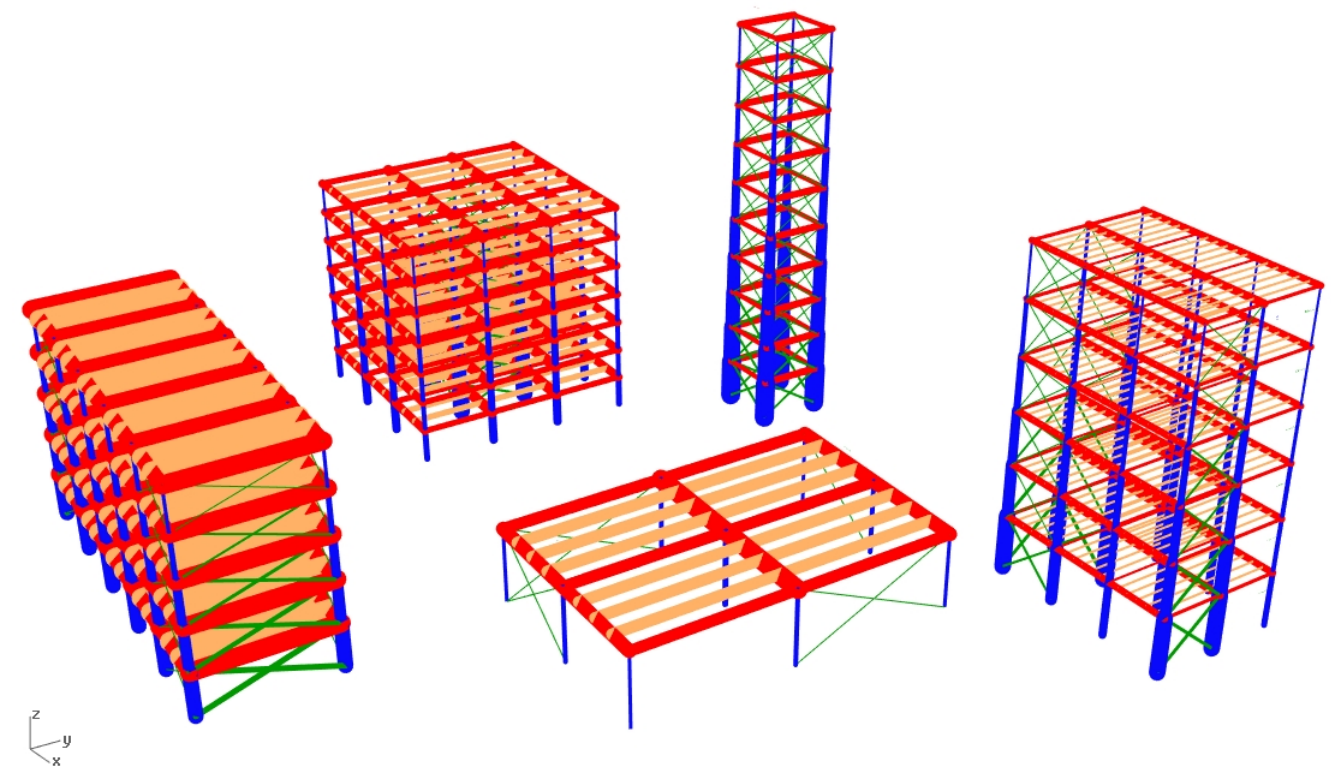

Figure 18: a small sample of the range of frame geometries that can be automatically generated using the described tool.

its ultimate aim, the tool has been named BEETLE2, which stands for Built Environment Tool for Low Environmental Externalities and it is freely available for public use within the Food4Rhino platform [53]. Results have shown that savings up to $23 \%$ are achievable for both steel mass and carbon emissions for a typical steel framed building. This is obtained without sacrificing the "need for speed' that often characterises construction projects. Additionally, the tool accounts for the inherent uncertainty of steel mass and embodied carbon coefficients, thus producing results in the form of a probability distribution. This minimises the risk of misleading decision-makers with a sense of false accuracy given by very definite numbers.

Even if the initial aim of the research was to develop a real-time design support, the optimisation algorithm does require some time to run, thus creating a time-lag between inputs and outputs. However, for highly complex structures this time is in the range of 20 to 60 seconds, which is completely acceptable to start with. The tool's applicability is limited to frames with rectangular layout plan and with constant span lengths.

Figure 18 gives a flavour of the structural systems the tool is able to handle, generate, and optimise. All of these do comply with existing standards and regulations for structural steel design of buildings in Europe. It can be seen that the tool is suitable to a significantly broad range of built assets, that should promote a rapid and wider uptake by the construction industry. Future work will expand the tool to other structural materials as well as cover an even wider range of built forms. Meanwhile, industry partners will test and further validate the tool's features and usefulness in design practice. Further collaborations and knowledge transfer activities would be most welcome to maximise the industrial and societal impact potentially coming out from this research. 


\section{Acknowledgements}

This research was supported by the UK's Engineering and Physical Sciences Research Council (EPSRC) [Grant No. EP/R01468X/1] and internal funds from Edinburgh Napier University, [Project No. 830425].

\section{References}

[1] EC, Roadmap to a Resource Efficient Europe - Communication from the Commission to the European Parliament, the Council, the European Economic and Social Committee and the Committee of the Regions COM, European Commission, 2011.

[2] EEA, Material Resources and Waste - 2012 Update, European Environment Agency, Copenhagen.

[3] M. M. Khasreen, P. F. Banfill, G. F. Menzies, Life-cycle assessment and the environmental impact of buildings: a review, Sustainability 1 (3) (2009) 674-701.

[4] F. Pomponi, A. Moncaster, Scrutinising embodied carbon in buildings: The next performance gap made manifest, Renewable and Sustainable Energy Reviews, (2017).

[5] P. Foraboschi, M. Mercanzin, D. Trabucco, Sustainable structural design of tall buildings based on embodied energy, Energy and Buildings 68 (Part A) (2014) 254-269.

[6] B. P. Weidema, M. Thrane, P. Christensen, J. Schmidt, S. Løkke, Carbon footprint: A catalyst for life cycle assessment?, Journal of Industrial Ecology 12 (1) (2008) 3-6.

[7] IPCC, Intergovernmental Panel on Climate Change. Working Group I Contribution to the Fifth Assessment Report of the Intergovernmental Panel on Climate Change. Climate Change 2013 - The Physical Science Basis [Stocker, T.F., D. Qin, G.-K. Plattner, M. Tignor, S.K. Allen, J. Boschung, A. Nauels, Y. Xia, V. Bex and P.M. Midgley (eds.)], Cambridge University Press, 2013.

[8] C. De Wolf, F. Pomponi, A. Moncaster, Measuring embodied carbon dioxide equivalent of buildings: A review and critique of current industry practice, Energy and Buildings 140 (2017) $68-80$.

[9] X. Su, X. Zhang, A detailed analysis of the embodied energy and carbon emissions of steelconstruction residential buildings in China, Energy and Buildings 119 (Supplement C) (2016) $323-330$.

[10] X. Zhang, F. Wang, Assessment of embodied carbon emissions for building construction in china: Comparative case studies using alternative methods, Energy and Buildings 130 (2016) $330-340$. 
[11] S. Hou, H. Li, Y. Rezgui, Ontology-based approach for structural design considering low embodied energy and carbon, Energy and Buildings 102 (2015) 75-90.

[12] D. Yeo, R. D. Gabbai, Sustainable design of reinforced concrete structures through embodied energy optimization, Energy and Buildings 43 (8) (2011) 2028-2033.

[13] J. M. Allwood, J. M. Cullen, M. A. Carruth, D. R. Cooper, M. McBrien, R. L. Milford, M. C. Moynihan, A. C. Patel, Sustainable materials: with both eyes open, UIT Cambridge Cambridge, 2012.

[14] F. Pomponi, B. D'Amico, Holistic study of a timber double skin façade: Whole life carbon emissions and structural optimisation, Building and Environment 124 (2017) 42-56.

[15] X. Su, X. Zhang, A detailed analysis of the embodied energy and carbon emissions of steelconstruction residential buildings in china, Energy and Buildings 119 (2016) 323-330.

[16] V. J. Gan, C. Chan, K. Tse, I. M. Lo, J. C. Cheng, A comparative analysis of embodied carbon in high-rise buildings regarding different design parameters, Journal of Cleaner Production 161 (2017) 663-675.

[17] V. J. Gan, J. C. Cheng, I. M. Lo, C. M. Chan, Developing a CO2-e accounting method for quantification and analysis of embodied carbon in high-rise buildings, Journal of Cleaner Production 141 (2017) 825-836.

[18] J. Basbagill, F. Flager, M. Lepech, M. Fischer, Application of life-cycle assessment to early stage building design for reduced embodied environmental impacts, Building and Environment $60(2013) 81-92$.

[19] F. Pomponi, B. DAmico, A. M. Moncaster, A method to facilitate uncertainty analysis in LCAs of buildings, Energies 10 (4) (2017) 524.

[20] G. Kang, T. Kim, Y.-W. Kim, H. Cho, K.-I. Kang, Statistical analysis of embodied carbon emission for building construction, Energy and Buildings 105 (2015) 326-333.

[21] J. P. Basbagill, F. Flager, M. Lepech, Measuring the impact of dynamic life cycle performance feedback on conceptual building design, Journal of Cleaner Production 164 (2017) 726-735.

[22] R. J. Balling, J. S. Lee, Simplified Model for Analysis and Optimization of Skyscrapers with Outrigger and Belt Trusses, Journal of Structural Engineering 141 (9) (2014) 04014231.

[23] H. Guan, Y.-J. Chen, Y.-C. Loo, Y.-M. Xie, G. P. Steven, Bridge topology optimisation with stress, displacement and frequency constraints, Computers \& structures 81 (3) (2003) 131-145.

[24] M. Arkinstall, T. Carfrae, Structural design and optimisation of the Beijing National Olympic Swimming Centre, Australian Journal of Structural Engineering 6 (3) (2006) 181-190. 
[25] M. C. Moynihan, J. M. Allwood, Utilization of structural steel in buildings, Proc. R. Soc. A 470 (2168) (2014) 20140170.

[26] C. Gibbons, Economic steelwork design, The Structural Engineer 73 (1995) 250-253.

[27] S. Naji, O. C. elik, U. J. Alengaram, M. Z. Jumaat, S. Shamshirband, Structure, energy and cost efficiency evaluation of three different lightweight construction systems used in low-rise residential buildings, Energy and Buildings 84 (Supplement C) (2014) 727-739.

[28] T. Hegazy, Optimization of construction time-cost trade-off analysis using genetic algorithms, Canadian Journal of Civil Engineering 26 (6) (1999) 685-697.

[29] R. T. Marler, J. S. Arora, Survey of multi-objective optimization methods for engineering, Structural and multidisciplinary optimization 26 (6) (2004) 369-395.

[30] M. Tan, Quantifying and integrating constructability into multi-objective steel floor framing design, Ph.D. thesis, Massachusetts Institute of Technology (2015).

[31] V. Yepes, J. V. Martí, T. García-Segura, Cost and $\mathrm{CO}_{2}$ emission optimization of precastprestressed concrete U-beam road bridges by a hybrid glowworm swarm algorithm, Automation in Construction 49 (2015) 123-134.

[32] R. Baldock, Structural optimisation in building design practice: case-studies in topology optimisation of bracing systems, Ph.D. thesis, University of Cambridge (2007).

[33] G. Rozvany, M. Zhou, The COC algorithm, part I: cross-section optimization or sizing, Computer Methods in Applied Mechanics and Engineering 89 (1-3) (1991) 281-308.

[34] R. Mijailović, G. Kastratović, Cross-section optimization of tower crane lattice boom, Meccanica 44 (5) (2009) 599-611.

[35] B. D'Amico, A. Kermani, H. Zhang, P. Shepherd, C. Williams, Optimization of cross-section of actively bent grid shells with strength and geometric compatibility constraints, Computers \& Structures 154 (2015) 163-176.

[36] Y. Ding, Shape optimization of structures: a literature survey, Computers \& Structures 24 (6) (1986) 985-1004.

[37] A. Beghini, M. Sarkisian, Geometry optimization in structural design, in: Proceedings of the 83rd SEAOC Annual Convention, Indian Wells, California, 2014.

[38] L. L. Beghini, J. Carrion, A. Beghini, A. Mazurek, W. F. Baker, Structural optimization using graphic statics, Structural and Multidisciplinary optimization 49 (3) (2014) 351-366.

[39] W. Dorn, R. Gomory, H. Greenberg, Automatic design of optimal structures, J. de Mechanique 3 (1964) 25-52. 
[40] M. Gilbert, A. Tyas, Layout optimization of large-scale pin-jointed frames, Engineering Computations 20 (8) (2003) 1044-1064.

[41] O. Sigmund, K. Maute, Topology optimization approaches, A comparative review, Structural and Multidisciplinary Optimization 48 (6) (2013) 1031-1055.

[42] L. L. Stromberg, A. Beghini, W. F. Baker, G. H. Paulino, Topology optimization for braced frames: combining continuum and beam/column elements, Engineering Structures 37 (2012) $106-124$.

[43] M. G. Sahab, V. V. Toropov, A. H. Gandomi, A review on traditional and modern structural optimization: problems and techniques, Metaheuristic Applications in Structures and Infrastructures (2013) 25-47.

[44] A. Moncaster, D. Hinds, H. Cruickshank, P. Guthrie, N. Crishna, K. Baker, K. Beckmann, P. Jowitt, Knowledge exchange between academia and industry, Proceedings of the Institution of Civil Engineers-Engineering Sustainability 163 (3) (2010) 167-174.

[45] D. Nethercot, Limit states design of structural steelwork, CRC Press, 2001.

[46] BS EN 1990:2002 Basis of Structural Design, British Standard Institution.

[47] BS EN 1993-1-1:2005 Design of steel structures - Part 1-1:General rules and rules for buildings, British Standard Institution.

[48] D. E. Knuth, The art of computer programming, Vol. 3, Pearson Education, 1997.

[49] E. Nunez-Moreno, E. Yandzio, Steel building design: Design data "Eurocode Blue Book" (P363), SCI, Tata Steel, BCSA, 2009.

[50] W. McGuire, R. H. Gallagher, R. D. Ziemian, Matrix Structural Analysis, 2nd Edition, Faculty Books, 2000.

[51] J. J. Azar, Matrix Structural Analysis: Pergamon Unified Engineering Series, Vol. 8, Elsevier, 2013.

[52] M. Lotteau, P. Loubet, G. Sonnemann, An analysis to understand how the shape of a concrete residential building influences its embodied energy and embodied carbon, Energy and Buildings 154 (Supplement C) (2017) 1-11.

[53] B. D'Amico, F. Pomponi, BEETLE2, http://www. food4rhino.com/app/beetle2, [Accessed: 2018-01-14] (2017).

[54] T. E. Oliphant, A guide to NumPy, Vol. 1, Trelgol Publishing USA, 2006.

[55] C. Ruegg, M. Cuda, J. Van Gael, Math.Net Numerics, http://numerics .mathdotnet . com, [Accessed: 2017-09-14] (2016). 